\title{
Effect of Post-Processing on the Dimensional Accuracy of Small Plastic Additive Manufactured Parts
}

\section{Keywords}

Laser Sintering, Fused Deposition Modelling, Nylon, Alumide ${ }^{\circledR}$, ABS, Post-Processing, dimensional accuracy

\section{Purpose}

To investigate the effect of post processing techniques on dimensional accuracy of Laser Sintering (LS) of Nylon and Alumide ${ }^{\circledR}$ and Fused Deposition Modelling (FDM) of Acrylonitrile Butadiene Styrene (ABS) materials.

\section{Methodology}

Additive Manufacturing (AM) of test pieces using Laser Sintering of Nylon and Alumide ${ }^{\circledR}$ powders, as well as the Fused Deposition Modelling of ABS materials were first produced. Next, post-processing of the test pieces involved tumbling, shot peening, hand finishing, spray painting, CNC machining and chemical treatment. Touch probe scanning of the test pieces were undertaken to assess the dimensional deviation, followed by statistical analysis using Chi-square and Z-tests.

\section{Findings}

The deviation ranges of the original built parts with those being subjected to tumbling, shot peening, hand finishing, spray painting, CNC machining or chemical treatment were found to be different. Despite the rounding of sharp corners and the removal of small protrusions, the dimensional accuracy of relatively wide surfaces of Nylon or Alumide ${ }^{\circledR}$ test pieces were not significantly affected by the tumbling or shot peening processes. The immersion of ABS test pieces into an acetone bath produced excellent dimensional accuracy.

\section{Research Limitations}

Only Nylon PA2200 and Alumide ${ }^{\circledR}$ processed through Laser Sintering and ABS P400 processed through Fused Deposition Modelling were investigated. Future work could also examine other materials as well as using parts produced with other AM processes.

\section{Practical Implications}

The service bureaus that produce prototypes and end use functional parts through AM will be able to apply the findings of this investigation.

\section{Originality/Value}

This research has outlined the differences of post processing techniques such as tumbling, shot peening, hand finishing, spray painting, CNC machining and chemical treatment. The paper discusses the advantages and disadvantages of each of those methods and suggests that the immersion of ABS test pieces into an acetone bath produced excellent dimensional accuracy. 


\section{Introduction}

Additive Manufacturing (AM) is defined as a process of joining materials to make objects from 3D model data, usually layer-upon-layer, as opposed to subtractive manufacturing (De Beer, 2013 and Manfredi et al., 2014). Depending on the type of technology, powder, liquid or solid based materials are used for AM processes. Although several AM technologies exist, all of them have five common steps. A digital 3D model is created using a CAD package. Next, the CAD model is converted into Standard Tessellation Language (STL) format. The STL file is sliced into Two-Dimensional (2D) thin cross sectional layers in $x-y$ plane which represent contours of the part. The 3D physical object is then constructed one layer atop each other, but not as a continuous z-coordinate, thus forming a stair-stepping effect in the z-direction (Latiff et al., 2013) until the part is completely built. Finally, the built model is removed from the machine, cleaned, and any supports removed depending on the AM technology used. Depending on the desired surface finish, the part may be further subjected to post processing techniques in order to improve its surface mechanical properties or to obtain a better aesthetic appearance. Figure 1 summarizes the steps involved that are common to most AM processes.

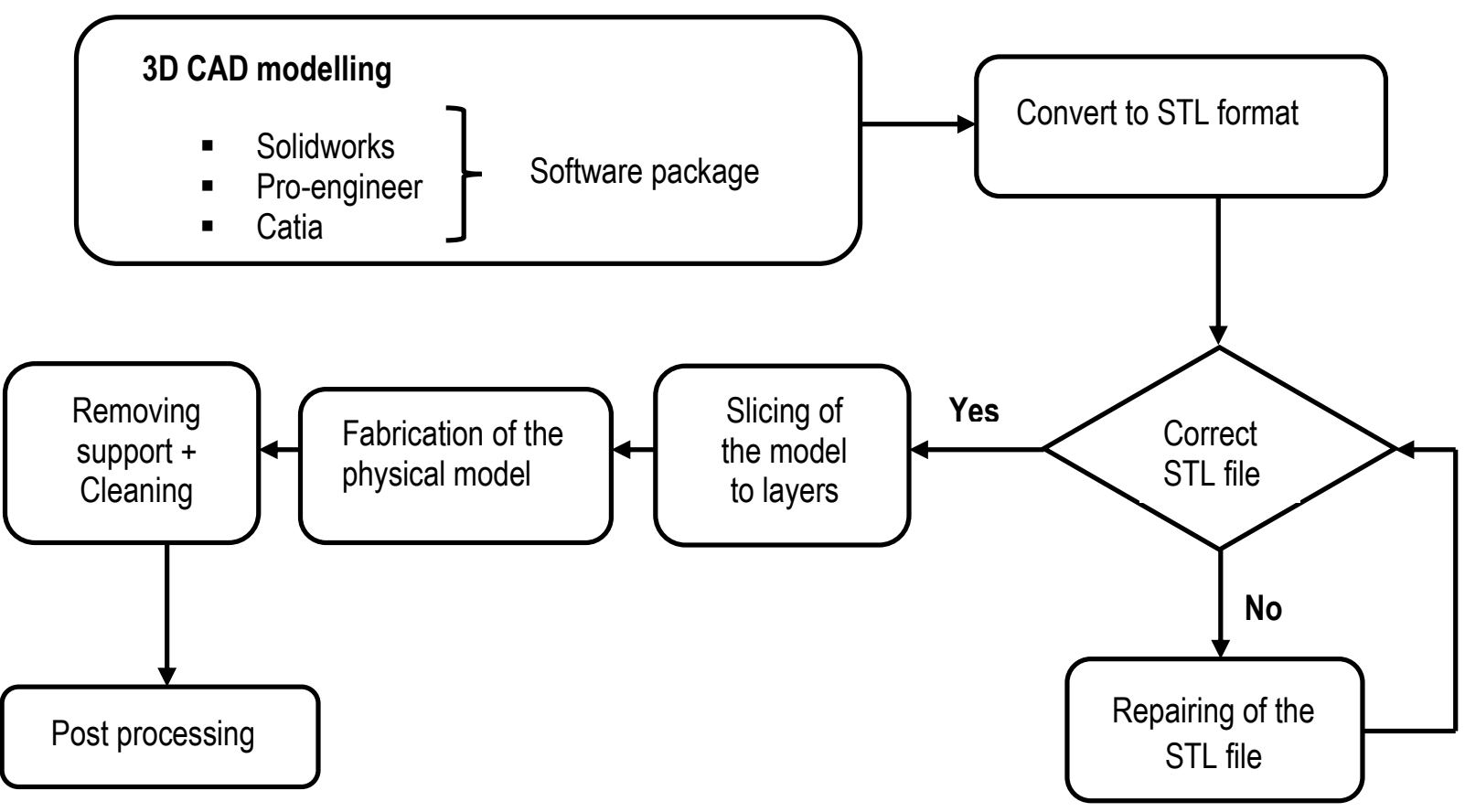

Figure 1: Flow chart of AM processes

\section{Laser Sintering process for plastic materials}

Laser Sintering (LS) is an AM process in which powdered material is fused by using laser energy to produce parts. Figure 2 shows the layout of an EOS P385 machine as an example. Plastic powder with particle size ranging from 20 to $100 \mu \mathrm{m}$ in diameter is stored in the powder supply bins. The recoater is filled with powder when positioned under one of the bins and deposits a layer of powder with a thickness of $150 \mu \mathrm{m}$ when moved across the platform. As it stops under the opposite bin, it is again filled with powder. A laser in continuous or pulse mode scans 2D slices of the design onto the powder and in the process generates the required heat for fusing the powder particles. The build platform is lowered one-layer thickness, a new layer of powder is deposited and the next slice of the design is scanned by the laser. This process is repeated until the part is completed. The excess powder from recoating falls into the overflow bins in a compartment below the build chamber (EOS GmBH, 2005). The un-sintered powder surrounding the parts is cleaned away and can be largely recycled together with the overflow powder once the build is completed. Support 
structures are not required with the LS process since the un-sintered powder supports the part during manufacturing.

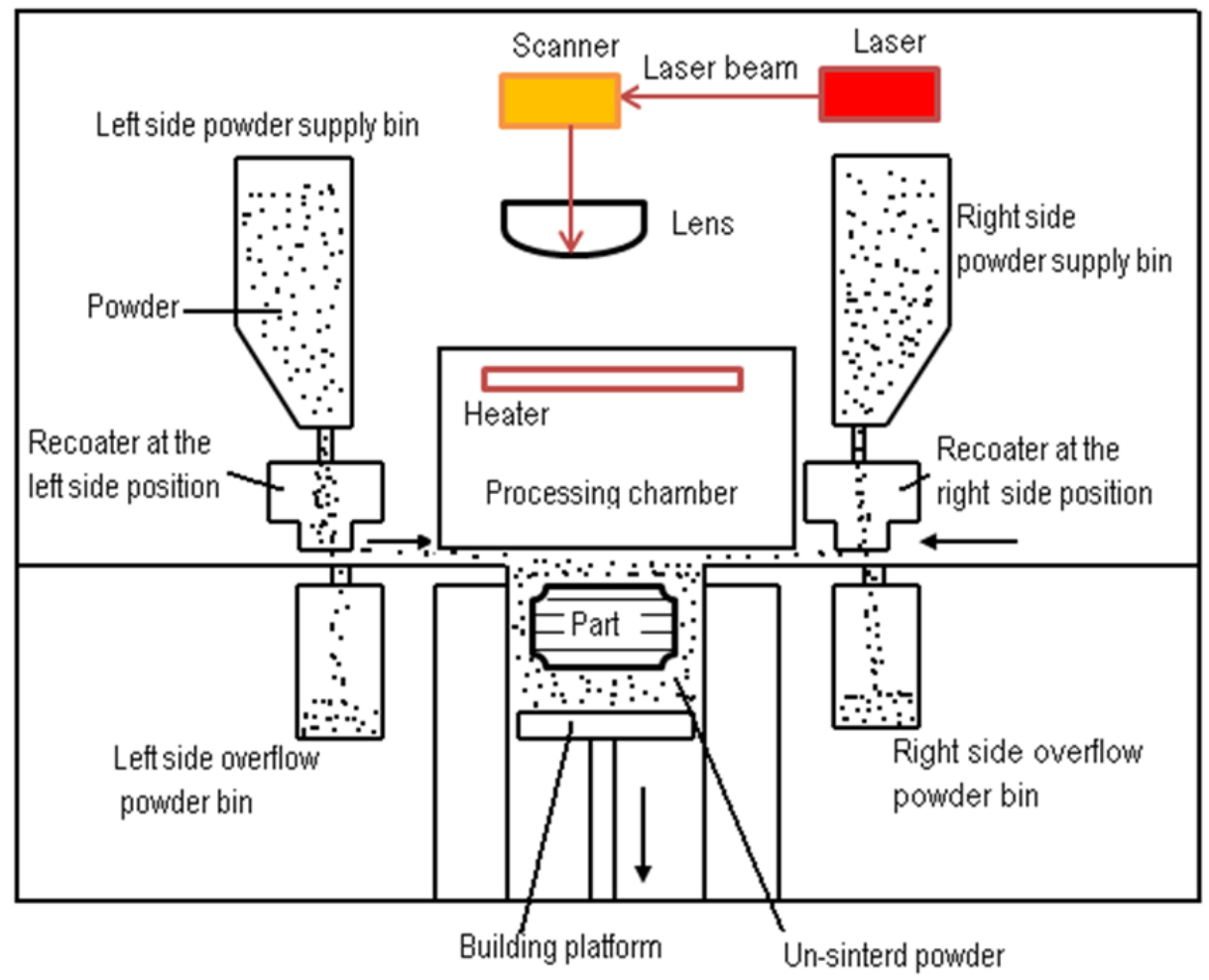

Figure 2: LS process for EOS P385 machine

\section{Surface finish and dimensional accuracy of laser sintered Nylon and Alumide ${ }^{\circledR}$ parts}

In commercial practices, it is not economical to use only virgin powder in the LS process. A mixture of virgin and used powders is recommended in order to compensate the high purchasing cost of the virgin powder and to minimize waste. Kruth et al. (2008) noted that long exposure of the polymer powder to heat when reused for further fabrication causes nonconstant consolidation conditions and a shift in the melting temperature, causing a drop in powder flowability and a rise in melt viscosity, thus preventing good sintering quality. This can be a potential source of rough surface and dimensional inaccuracy after a certain number of cycles of the used powder. The use of a mixture of $70 \%$ virgin and $30 \%$ re-used powder was recommended in order to produce parts with acceptable quality. Pham, Dotchev and Yusoff (2008) investigated the significance of the Mass Flow Rate (MFR) on the surface quality of laser sintered nylon PA2200 parts. It was found that the higher the MFR, the better the powder quality, thus leading to the production of parts with good surface finish and accurate dimensions. They recommended to consider a MFR higher than (25 to 27) g/10 min when mixing and blending used and new Nylon PA2200 powders in order to produce good quality parts. In order to avoid static forces which can hinder the spreading of the powder during the sintering process and causing unwanted sintering adjacent to the desired area thus affecting negatively the accuracy of the part, Goodridge et al. (2012) recommended 45 to $90 \mu \mathrm{m}$ as an optimal range of particle sizes for LS of macro parts. Shirazi et al. (2015) mentioned that although high energy density leads to good mechanical properties of the laser sintered parts; it can sometimes lead to inaccurate dimensions. Very little information is available in literature on improving the surface finish of laser sintered Alumide ${ }^{\circledR}$ parts, except using conventionally accepted techniques such as tumbling (De Beer et al., 2012), grinding, polishing and filing techniques (Urednik, 2013). 


\section{Overview of the Fused Deposition Modelling process}

FDM is a process which creates models where each layer is built by deposition of molten thermoplastic or wax material in the form of a filament available in spools or cartridges (Daneshmand et al., 2013). The nozzle of the FDM machine is heated and a thin filament of molten material is extruded and deposited onto the build platform according to the first layer of the slice file as shown in Figure 3. Since the air surrounding the head is maintained at a temperature which is below the material's melting point, the molten material quickly solidifies. The extrusion nozzle controlled by a CAM software that can move in the horizontal ( $x-y$ plane). When the first layer is completed, the building platform is lowered by one-layer thickness (z-axis) and the next layer is deposited. The process continues until the entire part is built. Support structures which are built during the process to support overhanging structures of parts can be later removed manually. When water soluble supports are employed, they may simply be dissolved with the latter approach being most efficient for complicated geometries (Daneshmand and Aghanajafi, 2012).

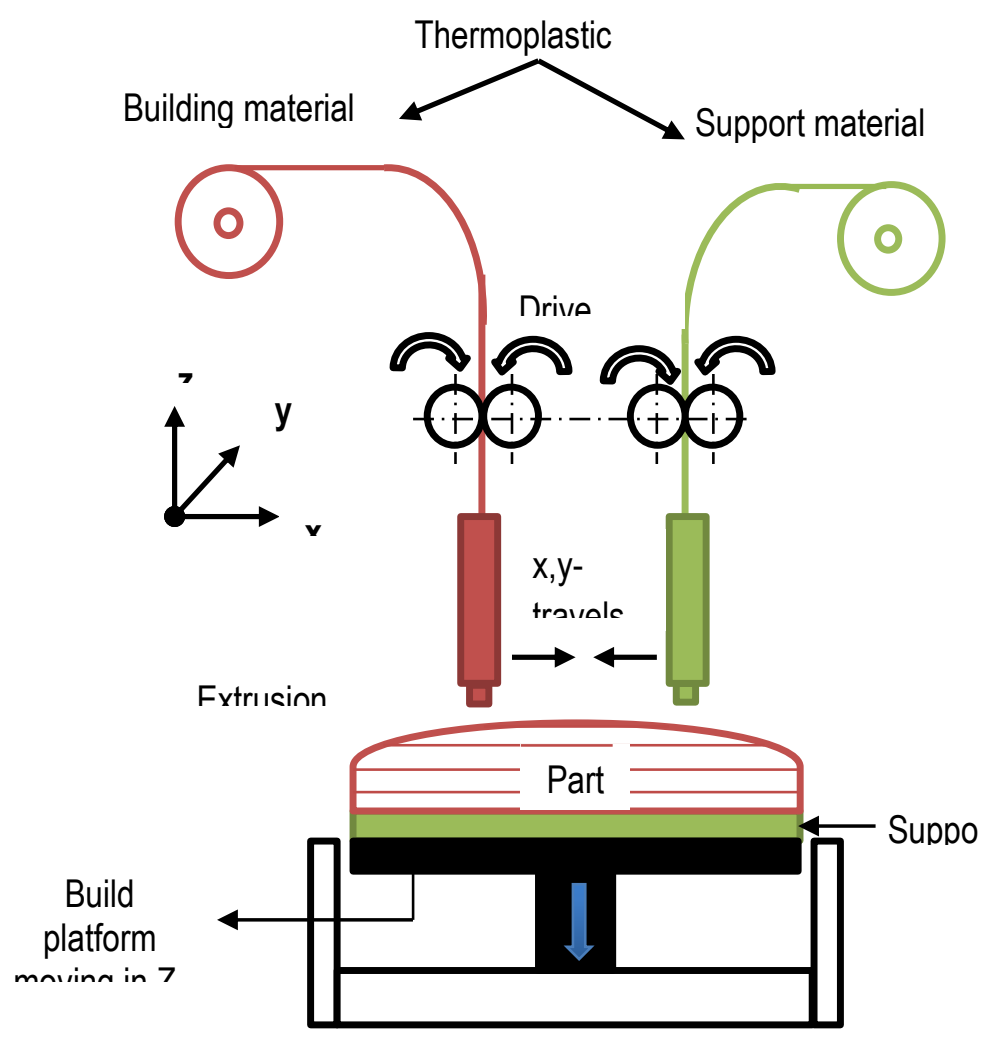

Figure 3: FDM process

FDM printers support the use of ABS plastics which are also frequently used in medical and automotive applications. Materials such as Polycarbonate (PC), Methyl methacrylate Acrylonitrile-Butadiene Styrene (ABSi), Polyphenyl sulfone (PPSF) and other blends of ABS (ABS-M30, ABS M30i, ABS-Plus, ABS-PC and ABS-P400) are also used for manufacturing parts through FDM technology (Mireles et al., 2011).

\section{Surface finish and dimensional accuracy of fused deposition modelled ABS parts}

Easy operation, inexpensive machinery, short building time, easy material changeability and good mechanical properties are advantages of FDM technology, rendering it the most 
popular AM method when compared to other processes such as Stereolithography (SLA), LS or Polyjet used for production of plastic parts (Noriega et al., 2013). Despite the above mentioned advantages of the FDM process, the poor surface finish and dimensional inaccuracy of parts resulting from this process is its main disadvantage (Krolczyk et al., 2014; Dzullijah et al., 2014 and Akande, 2015). As there is no single method of improvement of surface finish, Bual and Kumar (2014) highlighted that optimization of build orientation, slicing strategy (layer thickness), fabrication parameters optimization and post processing treatments are the four most commonly accepted methods which can be used separately or in combination to reduce the surface roughness of AM components. Figure 4 shows the geometrical process parameters of FDM technology, which influence the surface finish and the dimensional accuracy of manufactured parts.
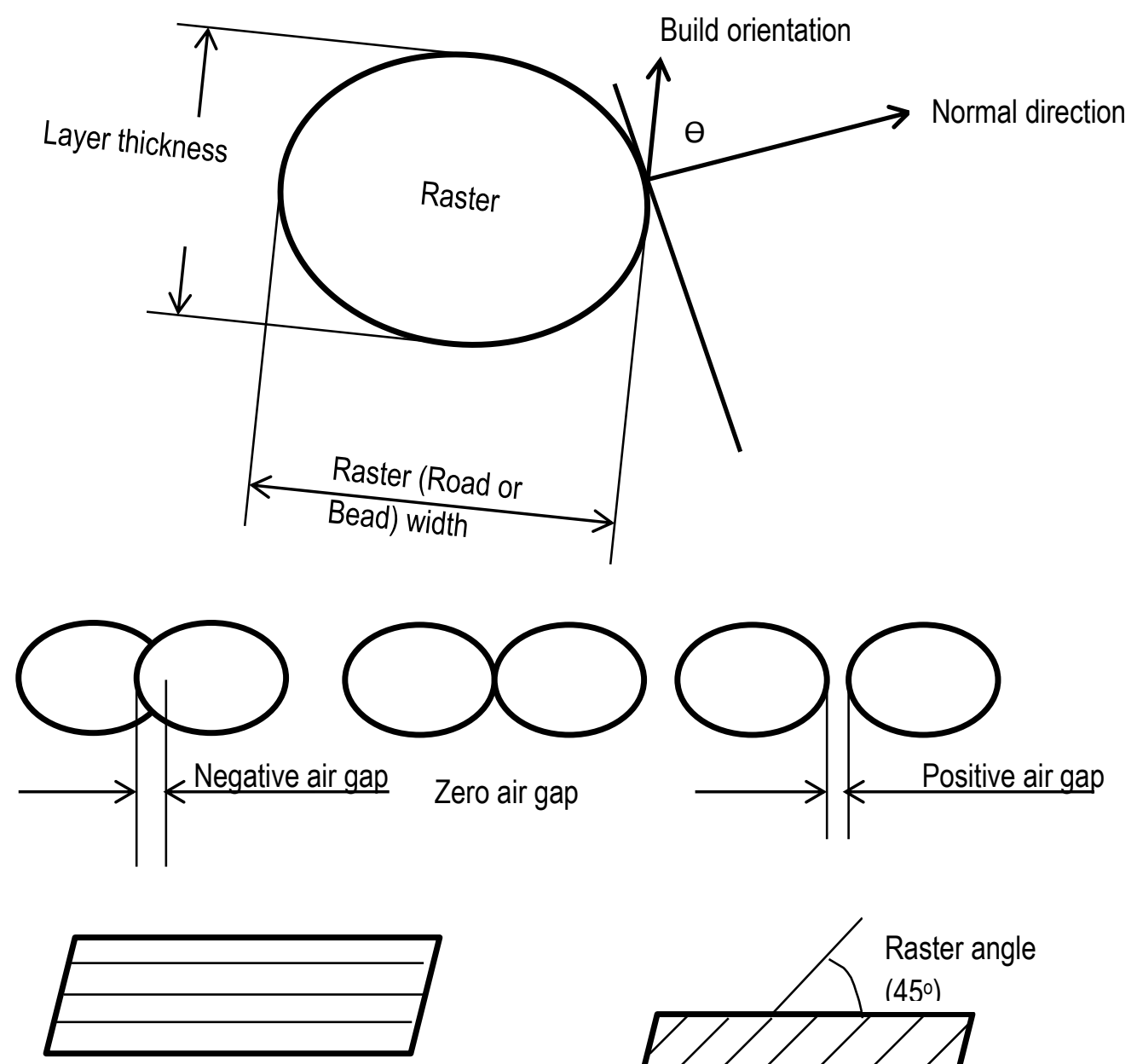

Longitudinal raster
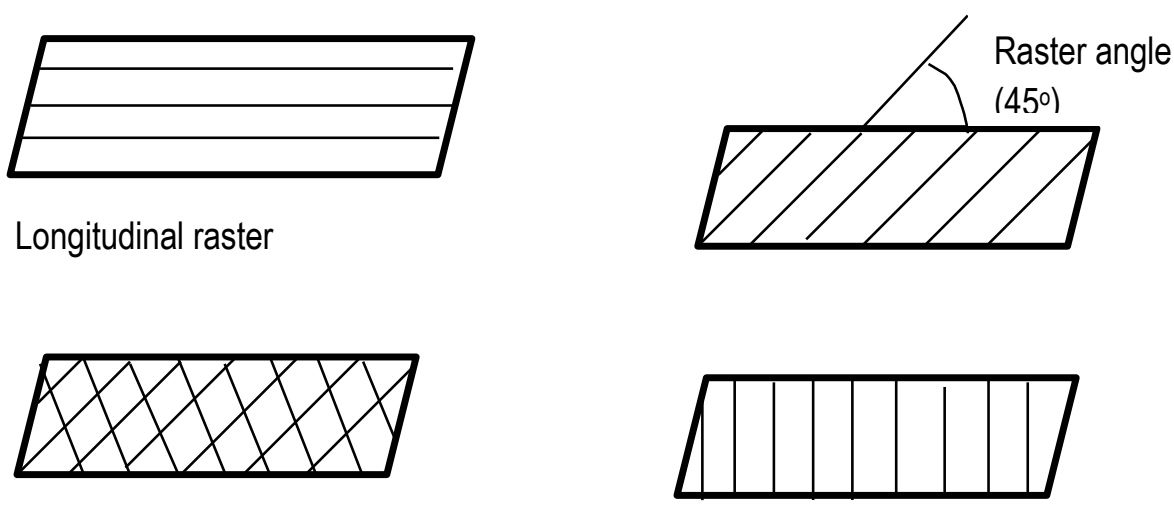

Criss-cross raster direction style

Transverse raster direction

Figure 4: Geometrical process parameters of FDM technology

Layer thickness and the raster width greatly influence the dimensional accuracy and the quality of the surface finish of ABS parts being produced through the FDM process. Air gaps were shown to have a significant effect on the dimensional accuracy while it has little 
influence on the surface finish (Nancharaiah, et al., 2010). Noriega et al. (ibid.) used an artificial neural network combined with an optimization algorithm to determine dimensional values of CAD model for the FDM process. Application of this methodology achieved a reduction in manufacturing error of approximately of $50 \%$ and $30 \%$ for external and internal dimensions respectively. McCullough and Yadavilli (2013) reported that improvement of the surface characteristics of the FDM process is one of the significant challenges to adopt ABS for medical applications. In order to ensure that an FDM component is completely watertight, they soaked the printed channels into a $25 \%$ concentrated acetone bath. Soaking of the components for periods varying from 1 to 8 hours in an aqueous solution of concentration ranging from 40 to 60 vol.\% acetone was found to be optimal to ensure that the surface becomes watertight and yet still preserving the microstructure of the component. An increase from $7 \mathrm{~nm}$ to $9 \mathrm{~nm}$ of surface roughness over an initial $5 \mu \mathrm{m}$ area was observed. The removal of $A B S$ material during an acetone soak caused pitting and subsequent deposition of $A B S$ on the surface formed peaks. To improve the surface quality of a tool fabricated from ABS using the FDM process, Kuo and $\mathrm{Su}(2013)$ used a vibratory filling mechanism where a mixture of a composite aluminium powder $(70 \%)$ and epoxy liquid resin $(30 \%)$ was used as a filling material to eliminate the parabolic surface profile of the tool. The surface finish was improved from 1710 to $276 \mu \mathrm{m}$ Ra. Galantucci et al. (2015) carried out a comparative study of the dimensional accuracy of two FDM machines namely an open -source Fab@Home Model 1 and a Stratasys FDM 3000 machine. The factorial analysis design of experiment to optimize the process parameters for improvement of the dimensional accuracy of ABS-P400 test pieces was used. It was found that for a rectangular specimen of length $L 1=18 \mathrm{~mm}$; width $\mathrm{L} 2=18 \mathrm{~mm}$ and height $\mathrm{H}=8 \mathrm{~mm}$, the manufactured specimens showed a percentage error of $-0.2 \%$ on $\mathrm{L} 1,+0.1 \%$ on $\mathrm{L} 2$ and $+1.9 \%$ on $\mathrm{H}$ for FDM 3000 system; and $-0.9 \%$ on $\mathrm{L} 1$, $-0.7 \%$ on $\mathrm{L} 2$ and $+3.2 \%$ on $\mathrm{H}$ for the open -source system. They attributed the negative errors in lateral dimensions to be caused by the material shrinkage while the increase in height was caused by issues with the raft layer. Raja (2016) indicated that metallization, electroplating, vapour deposition, thermal coating, electroless plating or autocatalytic plating and electrochemical polishing are other chemical processes that can be used to improve the surface characteristics of AM plastics. Extensive research has been done on improvement of the surface finish and its subsequent effect on the dimensional accuracy of LS and FDM parts using the process of parameter optimization (Zarringhalam, 2006; Raghunath and Pandey, 2007; Anoop et al., 2009; Shrivastava et al., 2010; Anoop et al., 2011; Tanay et al., 2013; Bual and Singh, ibid.; Daneshmand et al., ibid.; Singh, 2013; Lieneke et al., 2016 and Kitsakis et al., 2016). However, the obtained surface finish of LS or FDM parts could not achieve the required surface finish quality for end use functional parts, thus rendering post processing techniques through mechanical or chemical treatments a necessity for the AM industry. To the best knowledge of the authors, very little research is available in literature on the assessment of the detrimental effects of post processing techniques on the dimensional accuracy of AM parts.

\section{Dimensional accuracy of post processing techniques}

\subsection{Description and manufacturing of test pieces}

A test piece (Figure 5) was designed to investigate the effect of different post-processing techniques on small plastic parts manufactured through AM in terms of surface roughness and geometrical accuracy. The test piece was designed using SolidWorks software to have a base size of $60 \times 60 \mathrm{~mm}^{2}$ with a height of $19.20 \mathrm{~mm}$. The designed test piece had different planar surfaces with inclination angles varying from $0^{\circ}$ (horizontal) to $90^{\circ}$ (vertical) with an increment of $10^{\circ}$. This was to show the variation of the stair-step effect as a result of the AM processes with different inclination angles and to investigate the effect of the different postprocessing techniques on this. For each surface finishing technique, four standard test pieces were manufactured through LS using Nylon polyamide PA2200 and Alumide ${ }^{\circledR}$ powders and through FDM using ABS P400 thermoplastic as a feedstock material. In 
addition to this, one test piece was manufactured in each material that would serve as reference test piece, in the form of a control. In particular, the test pieces for CNC machining was designed slightly over sized at $60.72 \times 60.72 \times 19.56 \mathrm{~mm}^{3}$ to allow the milling of a thin layer from each of the surfaces. The test piece design incorporated small features in the form of truncated cones, protruding rectangles and round cavities for comparative investigation of the effects of different post processing techniques. A central hole was provided for clamping of the test piece during hand finishing, spray painting and CNC machining operations. Table 1 shows the process parameters used for manufacturing the Nylon, Alumide ${ }^{\circledR}$ and ABS test pieces.

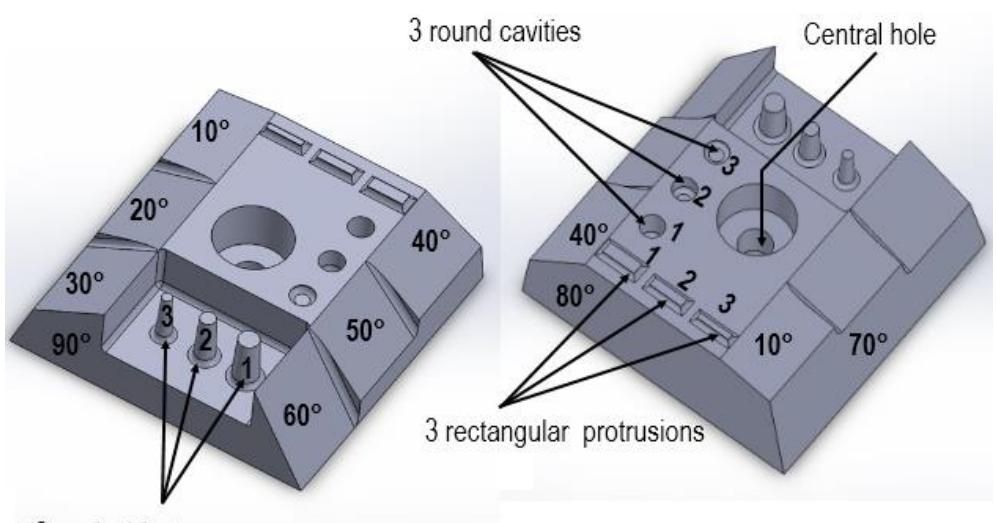

3 conical features

Figure 5: Test piece and its features

Table 1: Process parameters for AM of the test pieces

\begin{tabular}{|l|c|c|c|}
\hline Process parameters & \multicolumn{2}{|c|}{ LS } & FDM \\
\hline Materials & Nylon PA2200 & Alumide ${ }^{\circledR}$ & ABS P400 (white) \\
\hline Machine & EOS P385 & EOS P385 & Dimension SST 1200 \\
\hline Average grain size $(\mu \mathrm{m})$ & 56 & 60 & \\
\hline Raster width $(\mathrm{mm})$ & & & 0.5 \\
\hline Average melting point $\left({ }^{\circ} \mathrm{C}\right)$ & $172-180$ & $172-180$ & \\
\hline Laser power $(\mathrm{W})$ & 48 & 48 & \\
\hline Scanning speed $(\mathrm{mm} / \mathrm{s})$ & 4500 & 4500 & \\
\hline Part bed temperature $\left({ }^{\circ} \mathrm{C}\right)$ & 177.5 & 179 & \\
\hline Layer thickness $(\mu \mathrm{m})$ & 150 & 150 & \\
\hline Part build orientation $\left({ }^{\circ}\right)$ & 0 & 0 & \\
\hline Build rate $(\mathrm{mm} / \mathrm{hour})$ & 20 & 20 & \\
\hline Mass flow rate $(\mathrm{g} / 10$ min) & 30 & 30 & \\
\hline Scaling factor in $\mathrm{x}, \mathrm{y}$ and $z-$ & $1.0229 ; 1.030$ and & $1.0229 ; 1.030$ & \\
\hline directions & 1.018 & and 1.018 & Solid-Normal \\
\hline Model interior & & & Sparse \\
\hline Support fill & & & \\
\hline
\end{tabular}




\subsection{Touch probe scanning process}

A Renishaw ${ }^{\circledR}$ Cyclone RG24 Coordinate Measuring Machine (CMM) with a ruby ball stylus of $2 \mathrm{~mm}$ diameter and a scanning rate up to 140 points per second with a resolution of $0.1 \mathrm{~mm}$ was used to investigate the dimensional accuracy of the AM test pieces compared to the original CAD geometry; as well as to investigate the effects of the six post processing techniques on the dimensional accuracy of the AM test pieces. The "as built" Nylon, Alumide ${ }^{\circledast}$ and ABS test pieces were scanned, followed by one test piece from each post processing technique and the results were recorded as a point cloud and then converted to STL file with Trace scan 24A software. For each material, the STL file was processed using Geomagic Qualify software where the dimensions of the "as built" test pieces were compared to the geometric dimensions of the original CAD design. For each scanned sample, with a nominal deviation range of $\pm 0.1 \mathrm{~mm}$, the $3 \mathrm{D}$ scanning technology of Geomagic Qualify software generates a colour map (Figure 6) with the corresponding deviation ranges and produces a statistical report.

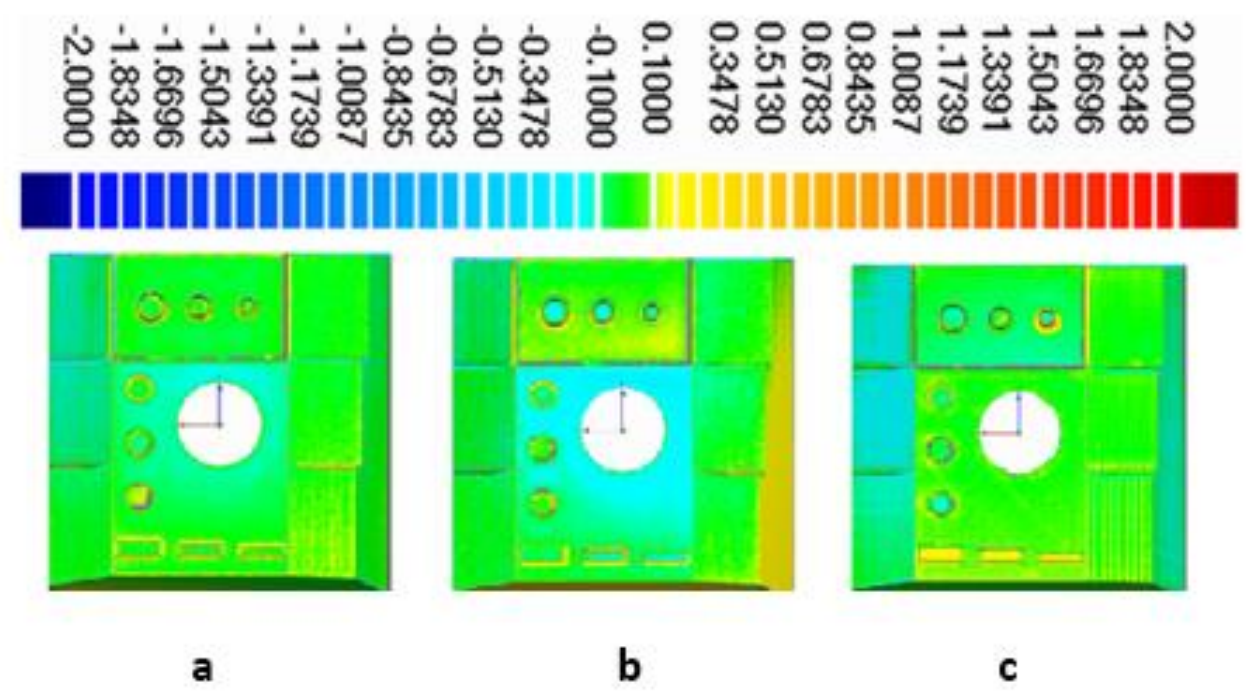

Figure 6: Dimensional accuracy of "as built" nylon (a), Alumide ${ }^{\circledR}$ (b) and ABS (c) test pieces compared to CAD geometry

It can be observed (Figure 6) that within a resolution of $0.1 \mathrm{~mm}$, the negative deviation ranges $(-0.348$ to- 0.1$) \mathrm{mm}$ that appear differently on the surfaces of the Nylon, Alumide ${ }^{\circledR}$ and ABS test pieces may have been caused by the shrinkage of the materials due to the solidification process. Positive deviation ranges $(0.1$ to 0.348$) \mathrm{mm}$ are also observed, especially at a $10^{\circ}$ surface angle where the stair-step effect is more pronounced and at the areas close to small features (protrusions, round cavities and conical features). This positive deviation may have been caused by the inability of the $2 \mathrm{~mm}$ diameter stylus to enter the grooves between adjacent steps or to move close to the basis of the small features.

\subsection{Post processing techniques}

To establish the significance level of the change in the geometry of plastic parts manufactured through LS and FDM processes when post processing techniques were applied for improvement of the surface finish, six post processing techniques were 
performed on the Nylon, Alumide ${ }^{\circledR}$ and ABS test pieces as summarized in Table 2. The results are discussed in the next section.

Table 2: Post processing techniques and procedures applied to test pieces

\begin{tabular}{|c|c|c|c|}
\hline \multirow{2}{*}{$\begin{array}{l}\text { Post } \\
\text { processing } \\
\text { technique }\end{array}$} & \multicolumn{3}{|c|}{ Material for test pieces } \\
\hline & Nylon & Alumide $^{\circledR}$ & ABS \\
\hline Tumbling & $\begin{array}{l}\text { Vibrating the test four } \\
\text { small abrasive stone } \\
\text { liquid at rotation spe } \\
\text { durations of } 1.5,3,4 \\
\text { respectively }\end{array}$ & $\begin{array}{l}\text { r pieces together with } \\
\text { ed wetted by a soapy } \\
\text { eds of } 1500 \text { rpm for } \\
.5 \text { and } 6 \mathrm{~h}\end{array}$ & $\begin{array}{l}\text { Similar process as for nylon and } \\
\text { Alumide }{ }^{\circledR} \text { but for a duration of } 1,2,3 \text { and } \\
4 \mathrm{~h}\end{array}$ \\
\hline Shot peening & $\begin{array}{l}\text { Blasting the four test } \\
\text { pieces with small } \\
\text { stainless steel balls } \\
\text { of } 0.5 \mathrm{~mm} \text { diameter } \\
\text { propelled by } \\
\text { compressed air at } \\
5 \text { Bar for durations } \\
\text { of } 2,4,6 \text { and } 8 \text { min } \\
\text { respectively }\end{array}$ & $\begin{array}{l}\text { Similar process as } \\
\text { for nylon butfor a } \\
\text { duration of } 1,2,3 \\
\text { and } 4 \text { min }\end{array}$ & $\begin{array}{l}\text { Similar process as for nylon but for a } \\
\text { duration of } 2,4,6 \text { and } 8 \text { min }\end{array}$ \\
\hline Hand finishing & \multicolumn{3}{|c|}{$\begin{array}{l}\text { Sanding and priming the four test pieces for } 45 \text { min. This was repeated for three of } \\
\text { the test pieces followed by an additional } 25 \text { min sanding and priming for two test } \\
\text { pieces. Lastly one test piece received a final } 25 \text { min sanding and priming. }\end{array}$} \\
\hline Spray painting & \multicolumn{3}{|c|}{$\begin{array}{l}\text { Progressive build-up of one additional layer of primer for each test piece i.e. first test } \\
\text { piece } 1 \text { layer, } 2^{\text {nd }} \text { two layers etc. All finished with one coat of silver paint each. }\end{array}$} \\
\hline \multirow[t]{5}{*}{$\begin{array}{l}\text { CNC } \\
\text { machining }\end{array}$} & Cutting tool & $\begin{array}{l}3 \mathrm{~mm} \text { diameter ball } \\
\text { cutter }\end{array}$ & \\
\hline & $\begin{array}{l}\text { Rotation speed of } \\
\text { the spindle }\end{array}$ & 4000 rpm & \\
\hline & Feed rate & $600 \mathrm{~mm} / \mathrm{min}$. & \\
\hline & Step-over & $0.2 \mathrm{~mm}$ & \\
\hline & Cutting depth & $0.3 \mathrm{~mm}$ & \\
\hline $\begin{array}{l}\text { Chemical } \\
\text { treatment }\end{array}$ & & & $\begin{array}{l}\text { Immersion into acetone bath at room } \\
\text { temperature for a duration of } 60 \mathrm{~s}\end{array}$ \\
\hline
\end{tabular}

\section{Results of Experiments}

\subsection{Preliminary statistical results}

Prior to the touch probe scanning process, it was observed that the chemically treated Nylon and Alumide ${ }^{\circledR}$ test pieces showed that neither acetone, formic acid nor resorcinol acid 
dissolved the surfaces of the test pieces; hence only a chemically treated ABS test piece was touch probe scanned. Preliminary statistical data generated by Geomagic Qualify ${ }^{\circledR}$ software for Nylon, Alumide ${ }^{\circledR}$ and ABS touch probe scanned test pieces were categorized into 24 deviation ranges to cover a range from -2.000 to $+2.000 \mathrm{~mm}$. Figures 7,8 and 9 show the comparison of dimensional accuracy of post processed test pieces, referenced to the geometry of the "as built" Nylon, Alumide ${ }^{\circledR}$ and ABS test pieces.

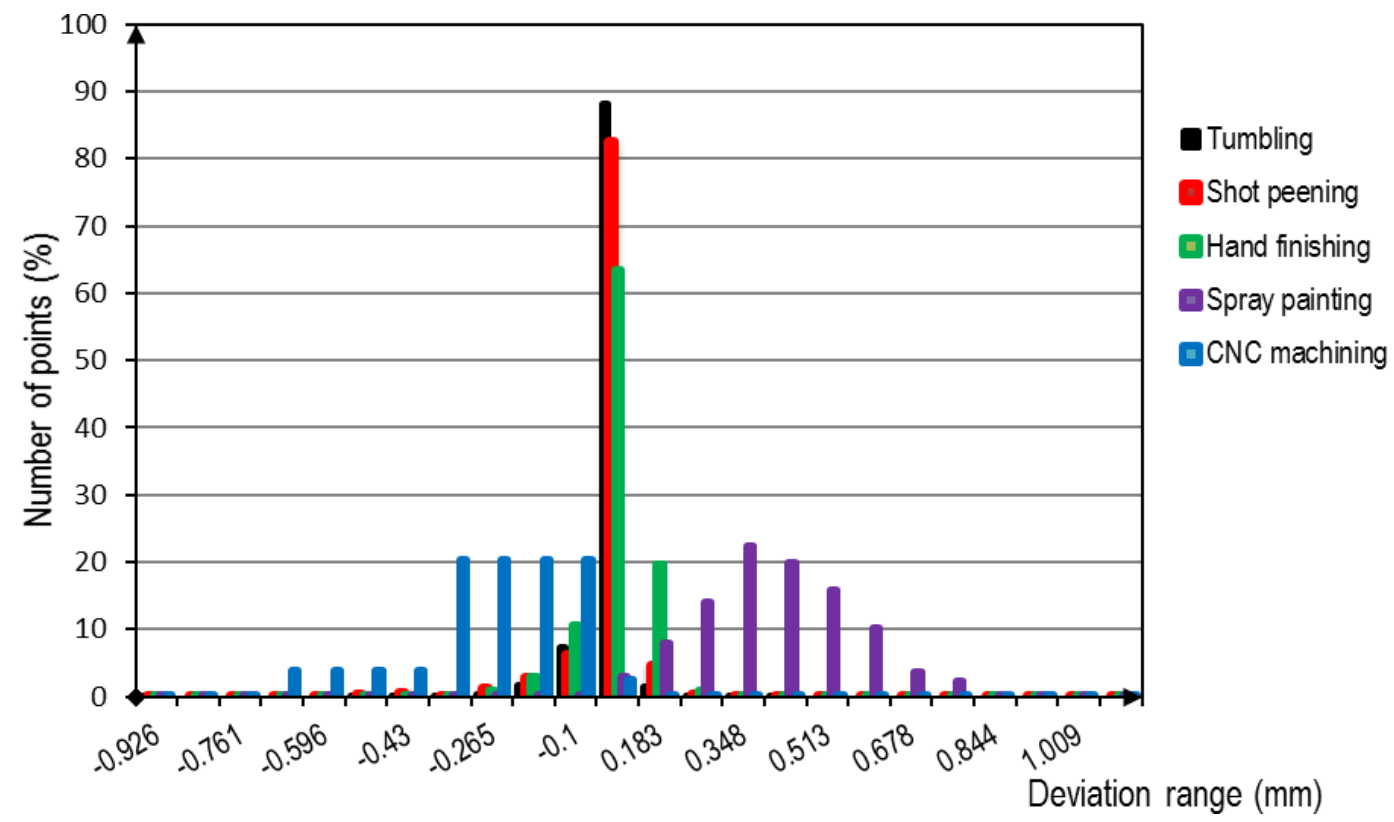

Figure 7: Comparison of dimensional accuracy of post processing techniques for nylon test pieces

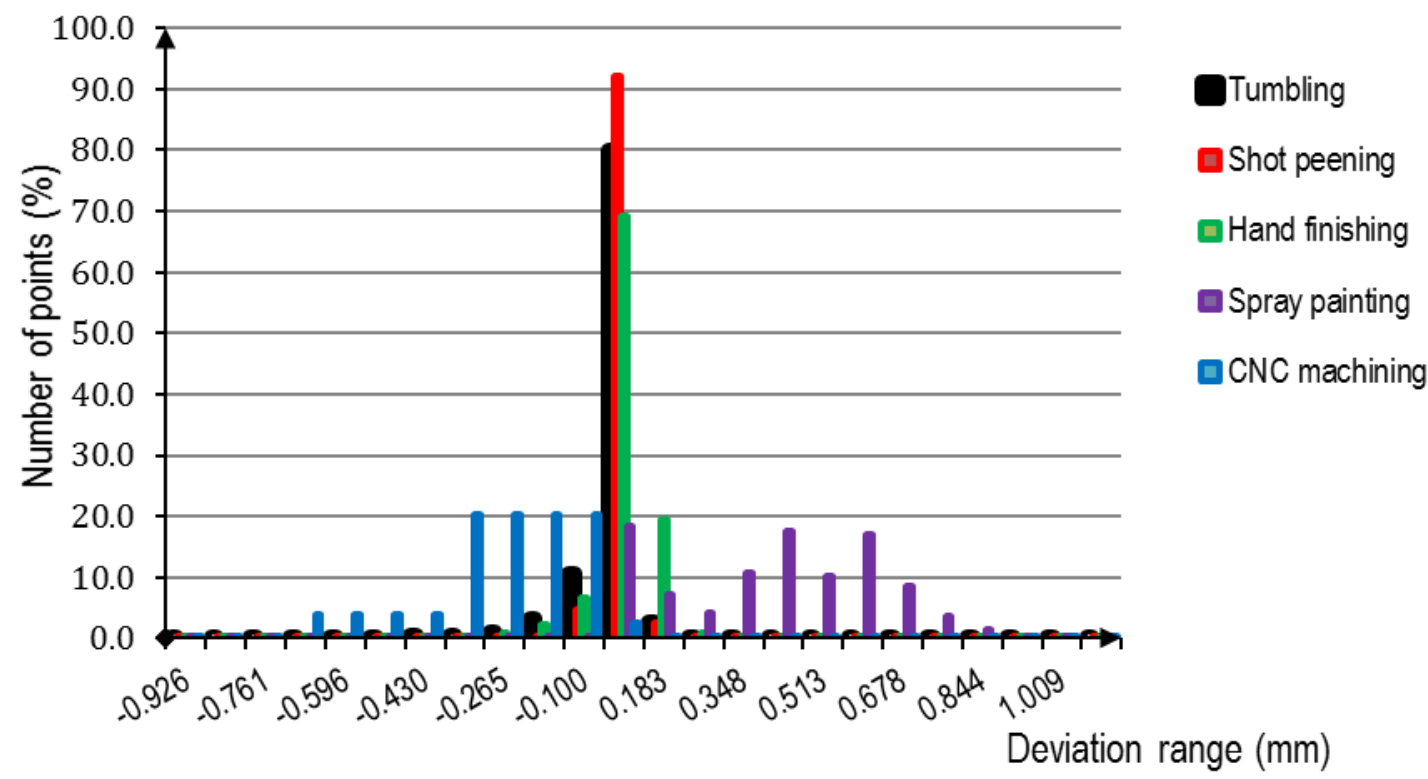

Figure 8: Comparison of dimensional accuracy of post processing techniques for Alumide ${ }^{\circledR}$ test pieces 


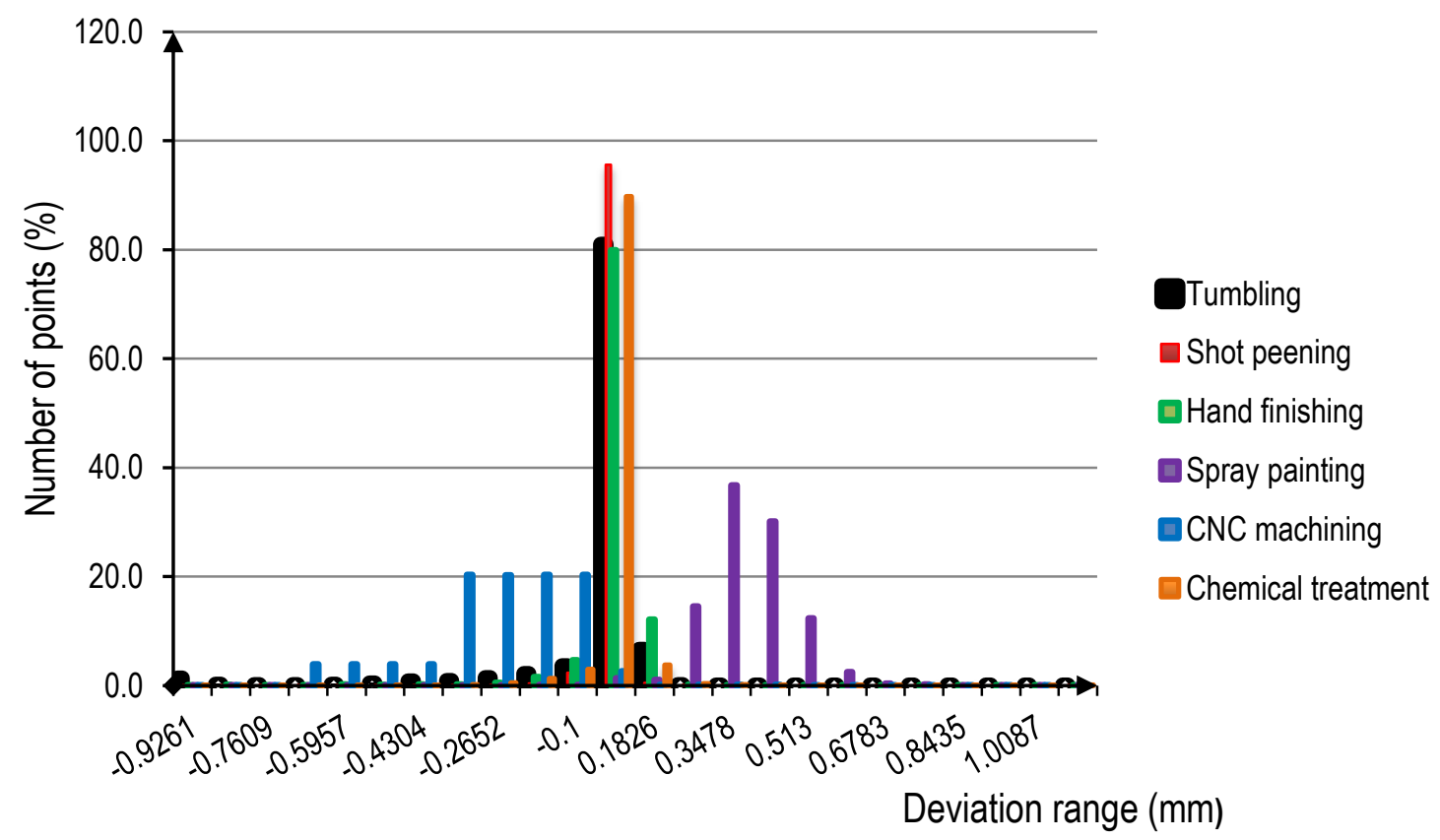

Figure 9: Comparison of dimensional accuracy of post processing techniques for $A B S$ test pieces

\subsection{Visual inspection of touch probe scanned test pieces}

The images along with the colour map generated by Geomagic Qualify ${ }^{\circledR}$ software enabled the visualization of the effects of each post processing technique on the geometry of the "as built" Nylon, Alumide ${ }^{\circledR}$ and ABS test pieces.

With $\pm 0.1 \mathrm{~mm}$ resolution, Figures 10,11 and 12 show the images obtained for post processed test pieces.

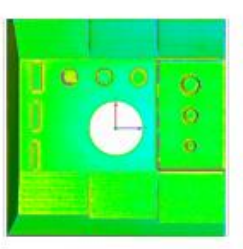

a

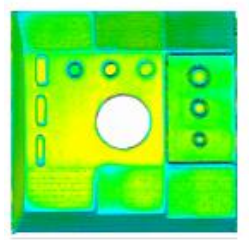

d

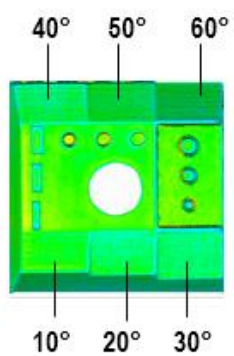

b

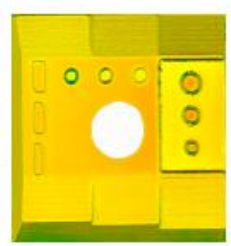

e

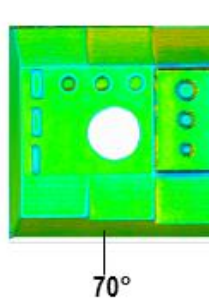

c

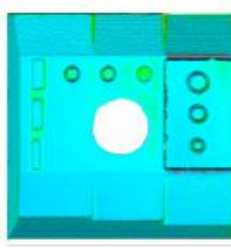

f

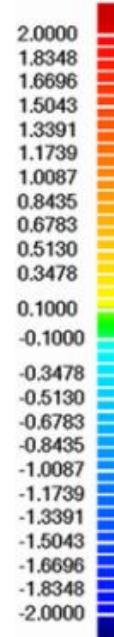

2.0000

Figure 10: Touch probe scan of Nylon test pieces: "as built" compared to CAD geometry (a), tumbled (b), shot peened (c), hand finished (d), spray painted (e) and CNC machined (f) compared to "as built" geometry 


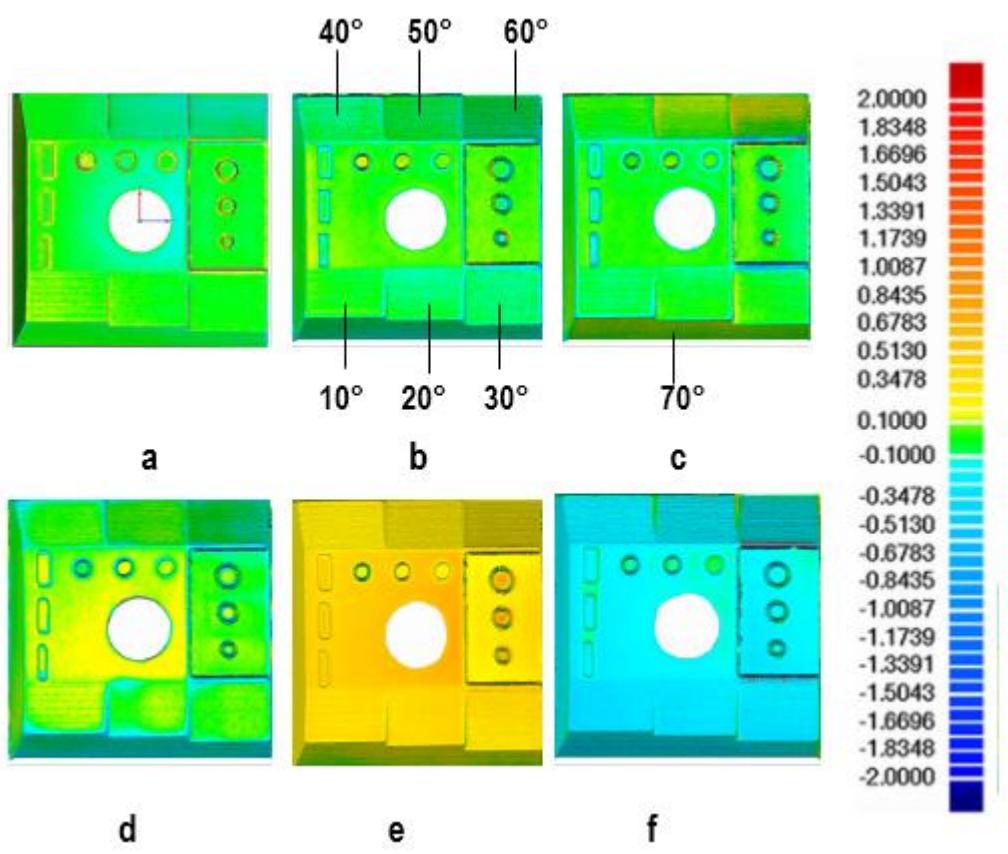

Figure 11: Touch probe scan of Alumide ${ }^{\circledR}$ test pieces: "as built" compared to CAD geometry (a), tumbled (b), shot peened (c), hand finished (d), spray painted (e) and CNC machined (f) compared to "as built" geometry

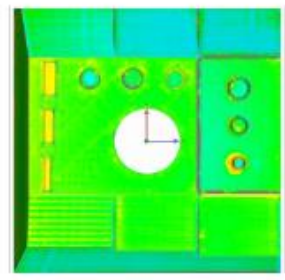

a
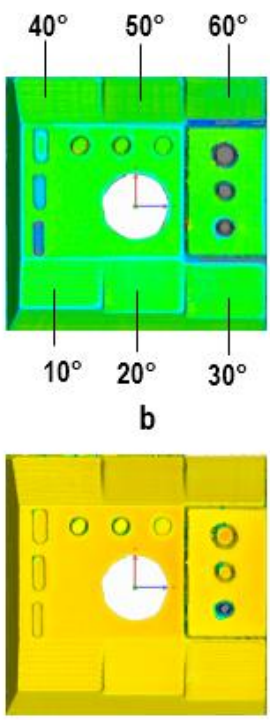
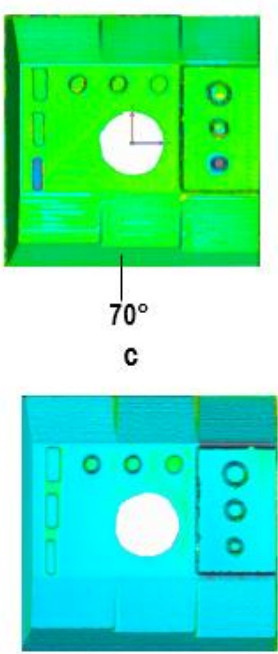

f

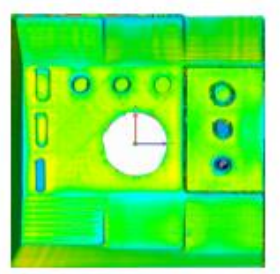

2.0000

1.8348

1.6696

1.5043

1.339

1.0087

0.8435

0.6783

0.5130

0.3478

0.1000

$-0.1000$

d

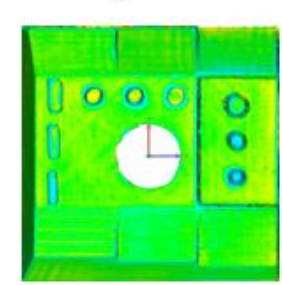

$-0.3478$

$-0.5130$

$-0.6783$

$-0.8435$

$-1.0087$

-1.1739
-1.3391

$-1.5043$

$-1.6696$

1.8348
-.0000

g

Figure 12: Touch probe scan of ABS test pieces: As "as built" compared to CAD geometry (a), tumbled (b), shot peened (c), hand finished (d), spray painted (e), CNC machined (f) and chemically treated $(g)$ compared to "as built" geometry 


\section{Analysis of Results, Observations and Conclusions}

\subsection{Test of homogeneity between "as built" and post processing techniques}

In addition to preliminary statistical results, there is a need of having a quantitative comparative measure to assess the extent to which the proportions of deviation ranges for "as built" and for any post processing technique are the same. For this purpose, a Chisquare test denoted by $\chi^{2}$, for a null hypothesis $-\mathrm{H}_{0}$ : the proportions of deviation ranges are the same as one compares "as built" to any one of the post processing techniques; and with different significance levels $\alpha=0.002 ; 0.01 ; 0.05$; and 0.1 is used. Applying the CHSQ.TEST function available in Microsoft Excel spread sheet, the probability ( $\mathrm{P}$-value) of observing a value of Chi -square $\chi^{2}$ at least as large as the observed value when the null hypothesis $\mathrm{H}_{0}$ is true; or in other words the smallest value of $\alpha$ for which $\mathrm{H}_{0}$ that can be rejected was calculated. A conclusion was reached by comparing the calculated P-value to the significance level $\alpha$ for the test. For all three investigated materials and for all six investigated post processing techniques, the P-value was obtained equal to zero, implying the rejection of the null hypothesis for all post processing techniques.

\subsection{Test for the difference in population proportions}

To establish which deviation range proportion (row) is significantly larger or smaller compared to the proportion of "as built" versus any post processing technique's proportion (columns), it is needed to test for the differences in population (treatment) proportions for each individual deviation range to both "as built" and tumbling for example. For each deviation range, the test statistic Z-observed $\left(Z_{\text {obs }}\right)$ calculated from the observed proportions will be compared to the value of the Inverse Normal Distribution, denoted $Z_{\alpha / 2}$ (Figure 13), associated with the level of significance $\alpha / 2$. The null hypothesis $\mathrm{H}_{0}$ : there is no difference in the true proportions of "as built" test piece versus tumbled test piece for example. The null hypothesis is rejected if $Z_{o b s}<-z_{\alpha / 2}$ or $Z_{o b s}>Z_{\alpha / 2}$.

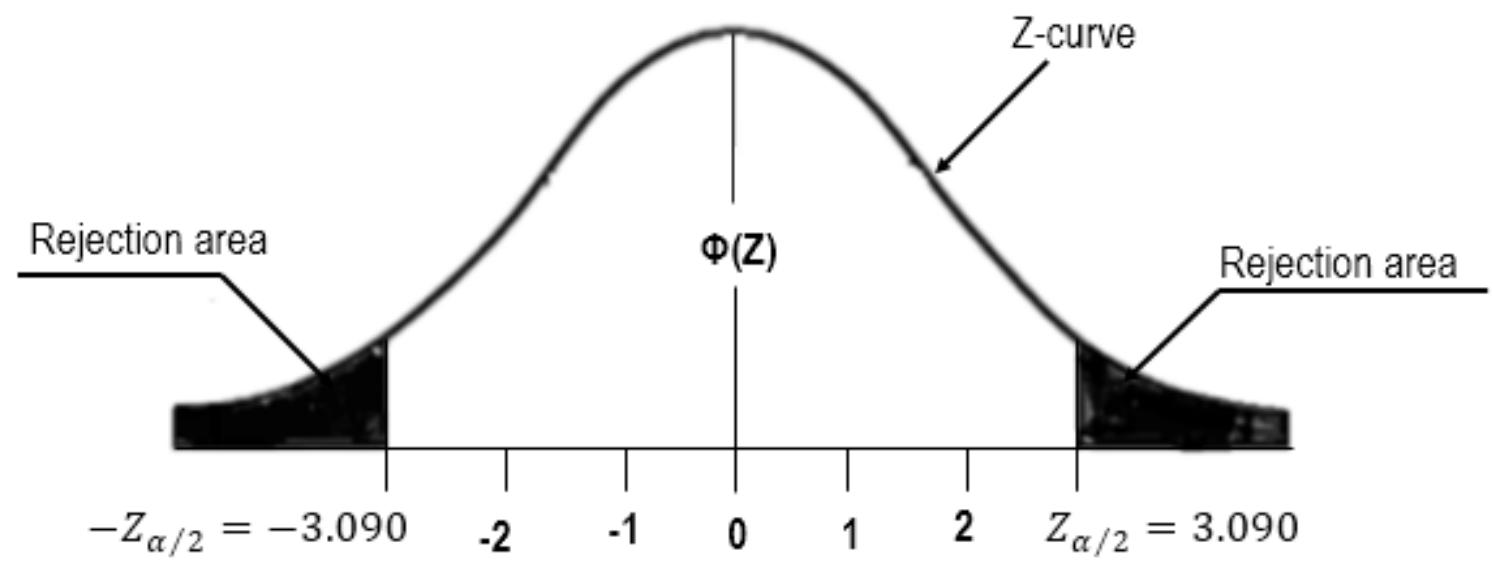

Figure 13: Standard normal $z$-curve for a significance level $\alpha=0.002$

The Z- test for differences in population proportions indicated that there existed a number of deviation ranges where the null hypothesis $\mathrm{H}_{0}$ was not rejected i.e. there was no difference in proportions of the number of points for both "as built" and a post processing technique. 
Tables 3 highlight the deviation ranges for which $\mathrm{H}_{0}$ is true, along with the percentage of number of observed points.

Table 3: Deviation ranges with no difference in population for ABS test pieces

\begin{tabular}{|c|c|c|c|c|c|c|c|c|c|c|}
\hline \multirow{3}{*}{\begin{tabular}{|l|} 
Post \\
processing \\
techniques
\end{tabular}} & \multicolumn{10}{|c|}{ Significance levels } \\
\hline & \multicolumn{2}{|c|}{$\begin{array}{c}\alpha=0.002(99.8 \%) \\
Z \alpha / 2=3.090\end{array}$} & \multicolumn{2}{|c|}{$\begin{array}{c}\alpha=0.01(99 \%), \\
Z \alpha / 2=2.575\end{array}$} & \multicolumn{2}{|c|}{$\begin{array}{c}\alpha=0.05(95 \%) \\
Z \alpha / 2=1.960\end{array}$} & \multicolumn{2}{|c|}{$\begin{array}{l}\alpha=0.1(90 \%) \\
Z \alpha / 2=1.645\end{array}$} & \multicolumn{2}{|c|}{$\begin{array}{l}\% \text { of observed } \\
\text { number of points }\end{array}$} \\
\hline & \multicolumn{2}{|c|}{$\begin{array}{l}\text { Deviation ranges } \\
\qquad(\mathrm{mm})\end{array}$} & \multicolumn{2}{|c|}{$\begin{array}{l}\text { Deviation ranges } \\
\qquad(\mathrm{mm})\end{array}$} & \multicolumn{2}{|c|}{$\begin{array}{l}\text { Deviation ranges } \\
\qquad(\mathrm{mm})\end{array}$} & \multicolumn{2}{|c|}{$\begin{array}{l}\text { Deviation ranges } \\
\qquad(\mathrm{mm})\end{array}$} & $\begin{array}{l}\text { For "as } \\
\text { built" } \\
01 \times 100\end{array}$ & $\begin{array}{l}\text { For the } \\
\text { process } \\
2 \times 100\end{array}$ \\
\hline \multirow{4}{*}{ Tumbling } & 0.513 & 0.596 & 0.513 & 0.596 & & & & & 0.1 & 0 \\
\hline & 0.596 & 0.678 & 0.596 & 0.678 & & & & & 0.1 & 0 \\
\hline & 0.678 & 0.761 & 0.678 & 0.761 & & & & & 0.1 & 0 \\
\hline & 1.009 & 2 & 1.009 & 2.000 & & & & & 0.1 & 0.1 \\
\hline $\begin{array}{l}\text { Shot } \\
\text { peening }\end{array}$ & -0.926 & -0.844 & -0.9261 & -0.8435 & -0.9261 & -0.8435 & -0.9261 & -0.8435 & 0 & 0 \\
\hline $\begin{array}{l}\text { Hand } \\
\text { finishing }\end{array}$ & -2 & -0.926 & -2 & -0.9261 & & & & & 0 & 0 \\
\hline \multirow{7}{*}{$\begin{array}{l}\text { Spray } \\
\text { painting }\end{array}$} & -2 & -0.926 & -2 & -0.9261 & & & & & 0 & 0 \\
\hline & -0.926 & -0.844 & -0.926 & -0.844 & -0.926 & -0.844 & -0.926 & -0.844 & 0 & 0 \\
\hline & -0.844 & -0.761 & -0.844 & -0.761 & -0.844 & -0.761 & -0.844 & -0.761 & 0 & 0 \\
\hline & -0.761 & -0.678 & -0.761 & -0.678 & & & -0.430 & -0.348 & 0 & 0 \\
\hline & -0.596 & -0.513 & 1.009 & 2.000 & & & & & 0 & 0 \\
\hline & -0.43 & -0.348 & & & -0.430 & -0.348 & & & 0.1 & 0.1 \\
\hline & 1.009 & 2 & & & & & & & 0.1 & 0.1 \\
\hline \multirow{2}{*}{$\begin{array}{l}\text { CNC } \\
\text { Machining }\end{array}$} & -0.926 & -0.844 & -0.926 & -0.844 & -0.926 & -0.844 & -0.926 & -0.844 & 0 & 0 \\
\hline & -0.844 & -0.761 & -0.844 & -0.761 & -0.844 & -0.761 & -0.844 & -0.761 & 0 & 0 \\
\hline \multirow{3}{*}{$\begin{array}{l}\text { Chemical } \\
\text { treatment }\end{array}$} & -2 & -0.926 & & & & & & & 0 & 0 \\
\hline & -0.926 & -0.844 & -0.926 & -0.844 & -0.926 & -0.844 & -0.926 & -0.844 & 0 & 0 \\
\hline & -0.844 & -0.761 & & & & & & & 0 & 0 \\
\hline
\end{tabular}

The value of $Z_{\alpha / 2}$ is sourced from Montgomery and Runger, 2011.

\section{p1: Proportion of points for "as built" test piece}

p2: Proportions of points for the post processed test piece

\subsection{Discussion and Interpretation of Results}

The computation of the Chi-square test for "as built" compared to tumbling, shot peening, hand finishing, spray painting, chemical treatment and CNC machining post processing techniques gives a $P$-value $=0$ for each of the post processing techniques for the Nylon, Alumide ${ }^{\circledR}$ and $A B S$ test pieces. Since the P-value is less than all the significance levels $0.002 ; 0.01 ; 0.05$ and 0.1 for the test, the Null Hypothesis $\mathrm{H}_{0}$ is rejected for all post processing techniques for all significant levels. This indicates that there are significant differences in the proportions of all the deviation ranges (rows) as one compares the "as built" test pieces to tumbled, shot peened, hand finished, spray painted, chemically treated or CNC machined test pieces (columns). However, the test statistic Z-observed $\left(Z_{o b s}\right)$ for differences in population proportions indicates that there exist a number of deviation ranges where the null hypothesis $\mathrm{H}_{0}$ is not rejected, i.e. there is no difference in proportions of the 
number of points for both "as built" and a post processing technique. For the "as built" and other post processing techniques, it is observed that the population proportions are the same in extreme positive or negative deviation ranges where a very small number of points $(0$ or $0.1 \%$ ) is found to fall into such deviation ranges. It can be observed from Tables 3,4 and 5 , that for all three investigated materials, the increase of significance levels from 0.002 to 0.01 , 0.05 and 0.1 has a little effect on the number of deviation ranges where no difference in population is observed. This indicates that the Z- test confirms that, for nylon, Alumide ${ }^{\circledR}$ and ABS test pieces, there exist strong evidences to conclude that the proportions in deviation ranges are not the same when one compares the "as built" part versus tumbling, shot peening, hand finishing, spray painting, CNC machining or chemical treatment post processing techniques applied to the test pieces.

Figures 14, 16, 17, 18 and 20 show the qualitative progressive dimensional deviations of the geometry of the post processed Nylon, Alumide ${ }^{\circledR}$ and ABS test pieces from "as built" test piece. Due to the limitations on time and funds, the touch probe scan was only performed on the "as built" and on the final post processed test pieces.

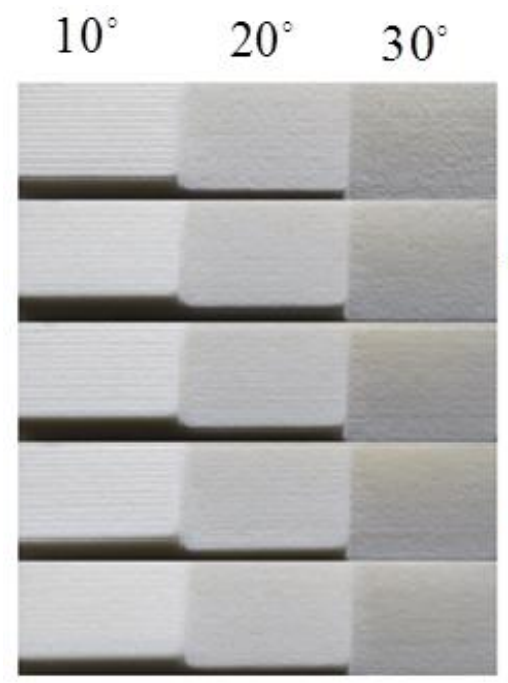

a

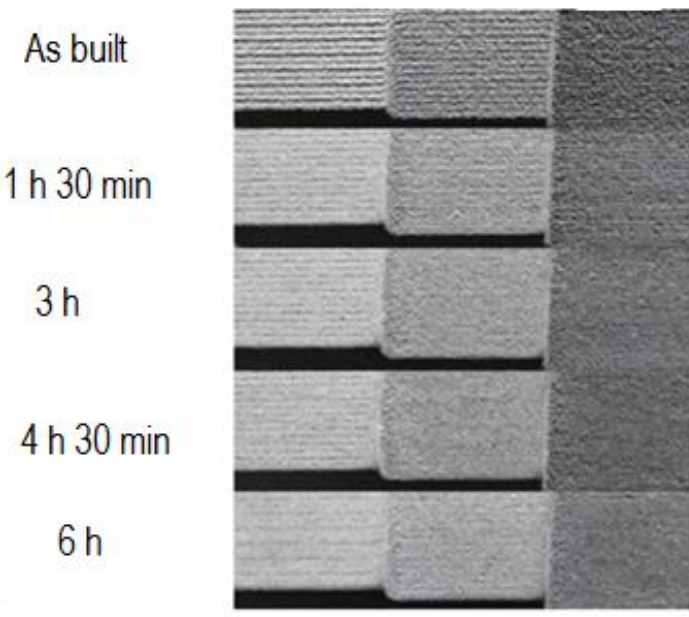

b

Figure 14: Progressively tumbled Nylon (a) and Alumide® test pieces

Within the $\pm 0.1 \mathrm{~mm}$ deviation range from the "as built" test piece, with a good uniform distribution of $\pm 0.1 \mathrm{~mm}$ deviation ranges across the relatively wide surfaces of the test piece, the tumbling technique applied progressively from 1.5 hour up to 6 hour with an increment of 1.5 hour, to both Nylon and Alumide ${ }^{\circledR}$ (Figure 14); and applied progressively from 1 hour to 4 hour with an increment of 1 hour to ABS test pieces, produced very good dimensional accuracy. $88.3 \%, 80.1 \%$ and $81 \%$ of the total number of touch probe scanned points on the surfaces of the test pieces were achieved for the nylon, Alumide ${ }^{\circledR}$ and ABS test pieces respectively (Figures 7,8 and 9). For all three materials, the tumbling technique was characterized by the rounding of sharp corners, wearing away of small protrusions, and the breaking off of the conical features (Figures 10b, 11b, 12b and 14c). Significant delamination of fibers from FDM part at the areas with sharp edges is particularly observed with the tumbling of ABS test pieces (Figure 15). 


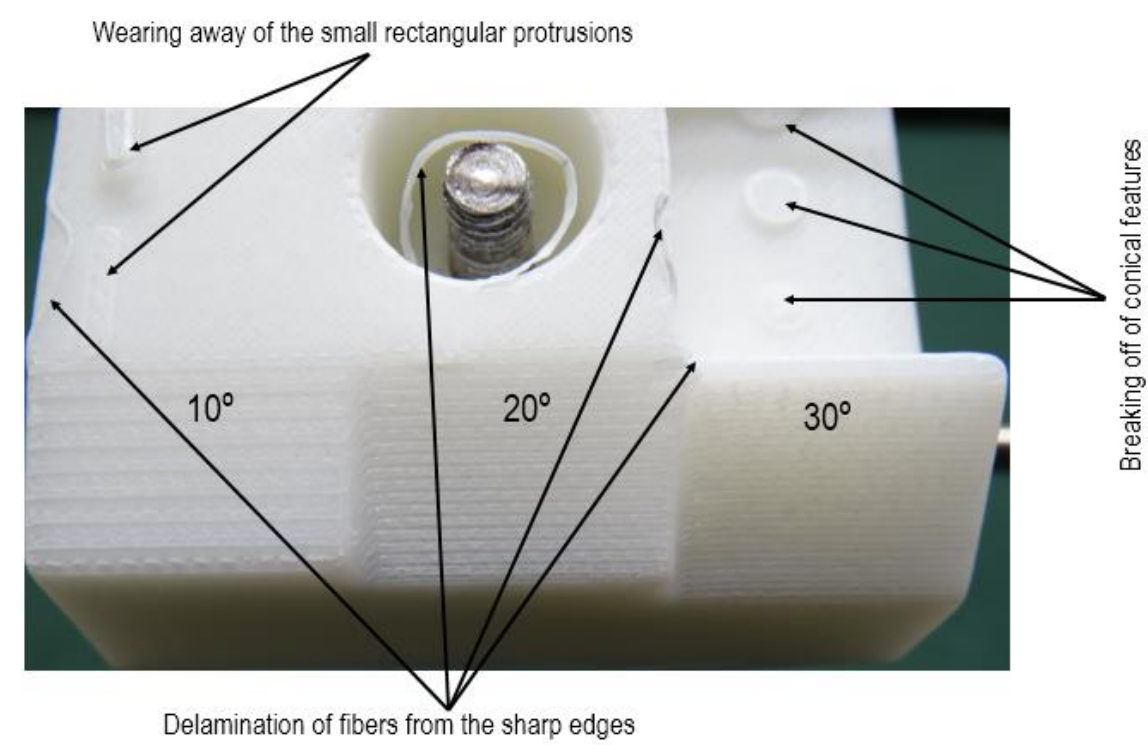

Figure 15: Problems associated with the tumbling of ABS test pieces

For all three materials, the shot peening technique applied progressively up to 8 minutes (Table 2 and Figure 16) produced a very good uniform distribution of $\pm 0.1 \mathrm{~mm}$ deviation range across relatively wide surfaces, leading to very good dimensional accuracy for Nylon test piece where $82.6 \%$ of the total number of points fell into the $\pm 0.1 \mathrm{~mm}$ deviation range (Figure 7). Up to 4 minutes and 8 minutes, excellent dimensional accuracy rates of $92.1 \%$ and $95.6 \%$ were obtained for Alumide ${ }^{\circledR}$ and ABS test pieces respectively (Figures 8 and 9). However, shot peening is generally characterized by the wearing away of small protrusions and sharp corners and a possible concentration of shots into confine area such as corners as the process is manually conducted. For ABS test pieces, the shot peening delaminates the external layers of relatively wide surfaces. This is more pronounced on $10^{\circ}, 20^{\circ}$ and $30^{\circ}$ surface inclination angles where the stair step effect is much more evidenced (Figure 16c).

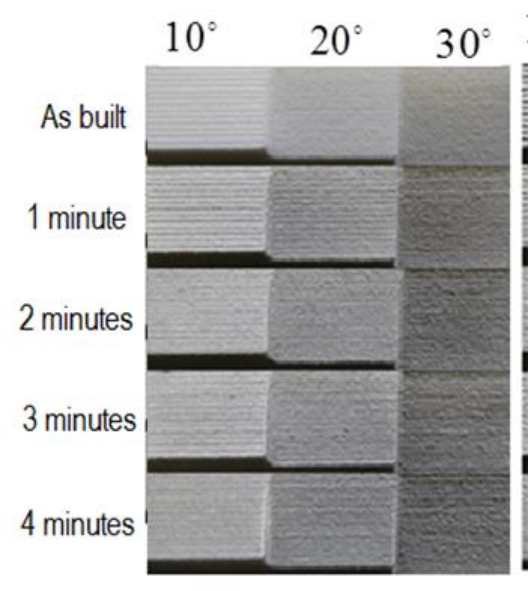

a

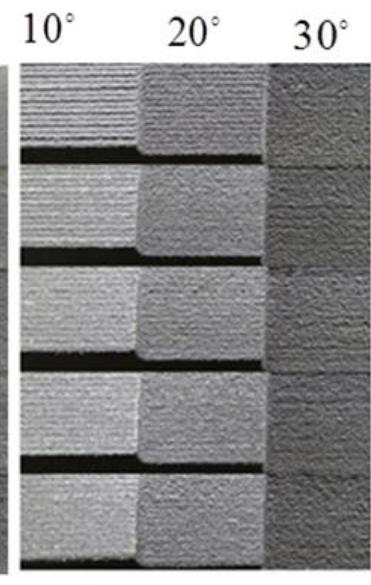

b

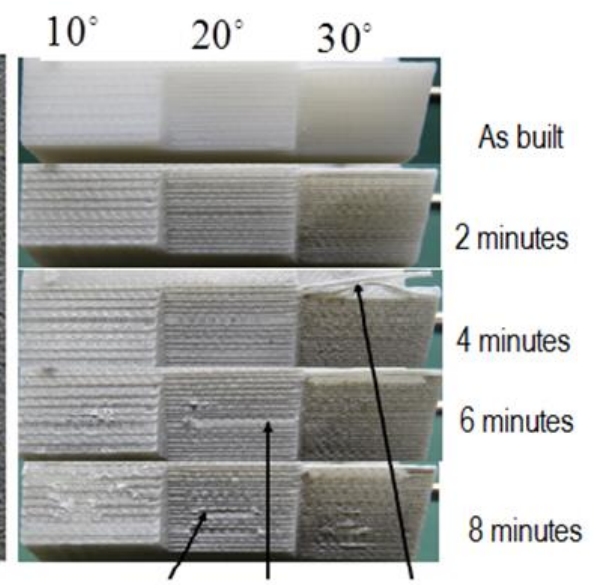

Delamination of external layers

C

Figure 16: Progressively shot peened Nylon (a), Alumide ${ }^{\circledR}$ (b) and ABS test pieces (c)

With a generalized lack of consistency in a uniform distribution of deviation ranges even across individual surfaces (Figures 10d, 11d, 17a and 17b ), within the $\pm 0.1 \mathrm{~mm}$ deviation 
range from the "as built" test pieces, hand finishing performed for a total period of 5 hours and 20 minutes produced satisfactory dimensional accuracy for Nylon and Alumide ${ }^{\circledR}$ with $63.5 \%$ and $69.2 \%$ of the total number of touch probe scanned points on the surfaces of the Nylon and Alumide ${ }^{\circledR}$ test pieces respectively. For the ABS test pieces, (Figures 12d and 17c) despite the lack of consistency in a uniform distribution of the $\pm 0.1 \mathrm{~mm}$ deviation range, it can be stated that very good dimensional accuracy was achieved as the rate of points falling within the $\pm 0.1 \mathrm{~mm}$ deviation range was raised to $80 \%$.

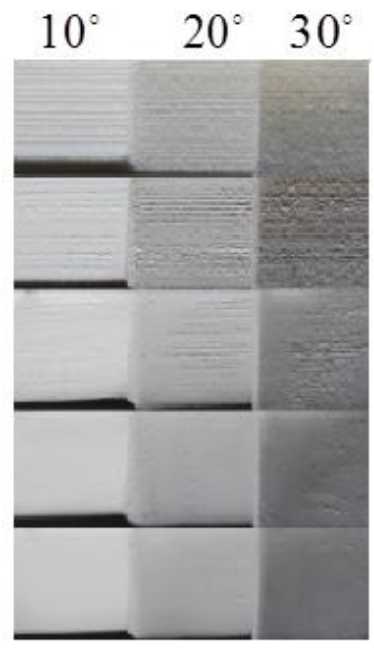

a

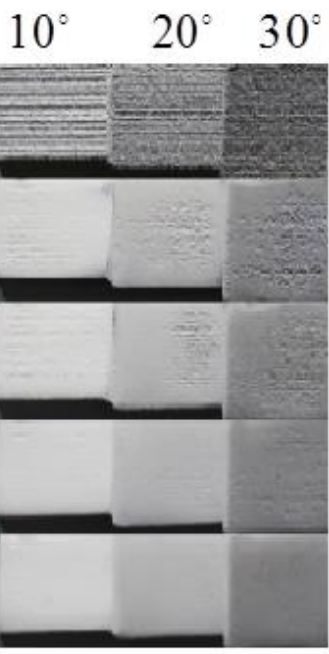

b

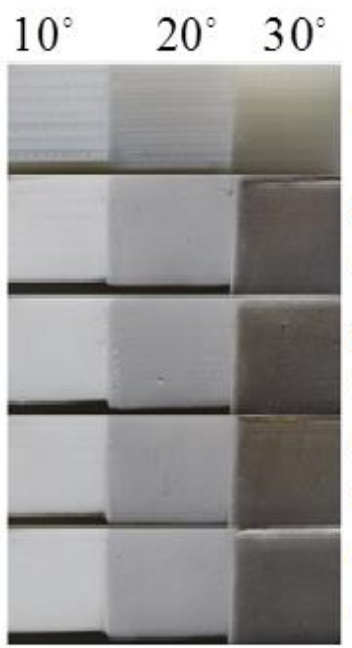

As built

2 sands +2 layers

epoxy primer

3 sands +4 layers

epoxy primer

5 sands +4 layers

epoxy primer

9 sands +6 layers

epoxy primer

C

Figure 17: Progressively hand finished Nylon (a), Alumide ${ }^{\circledR}$ (b) and ABS (c) test pieces

Spray painting (Figures 10e, 11e, 12e and 18) was generally dominated by consistent and uniform distribution of significant positive deviation ranges across almost the entire test piece for all three materials because of a build-up of paint on the surfaces. Within $\pm 0.1 \mathrm{~mm}$ deviation range poor dimensional accuracy was produced for Nylon $(3 \%)$, Alumide ${ }^{\circledR}(18.3 \%)$ and for ABS (1.3\%).

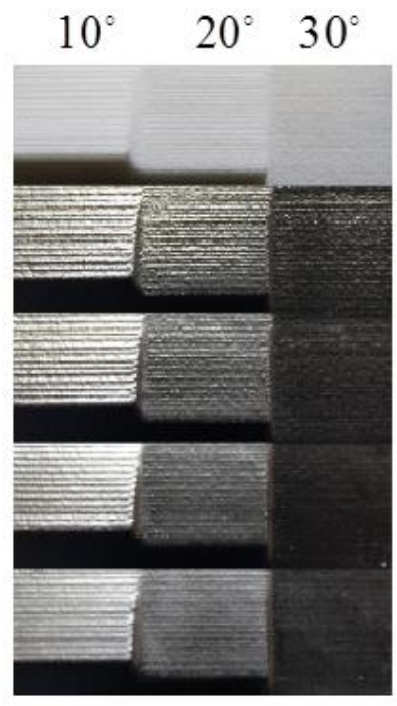

a

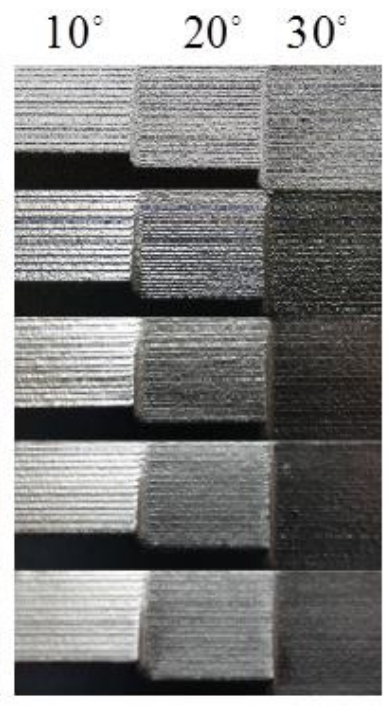

b

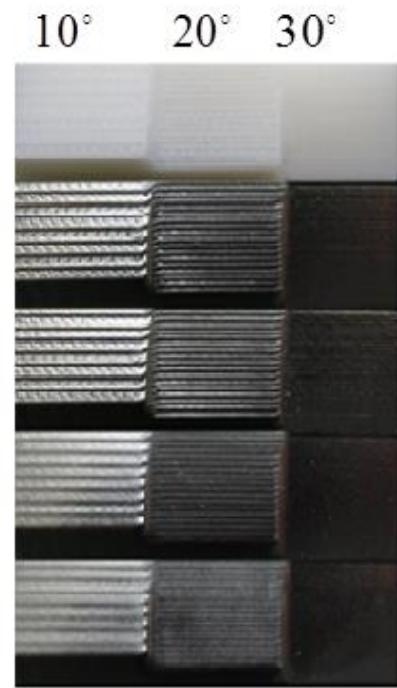

As built

1 primer coat +

1 silver coat

2 primer coats +

1 silver coat

3 primer coats +

1 silver coat

4 primer coats +

1 silver coat

Figure 18: Progressively spray painted Nylon (a), Alumide ${ }^{\circledR}$ (b) and ABS (c) test pieces 
CNC machining (Figures 10f, 11f 12f, and 19) showed a trend of producing negative deviation ranges close to the targeted $\pm 0.1 \mathrm{~mm}$ deviation range from the "as built" test piece. These unexpected results indicate that excess material has been removed from the surfaces of the test pieces. The repeated error for the all three CNC machined test pieces may have been caused by improper setup or calibration during the setting of the cutting parameters of the machine in the vertical direction (Z-axis).

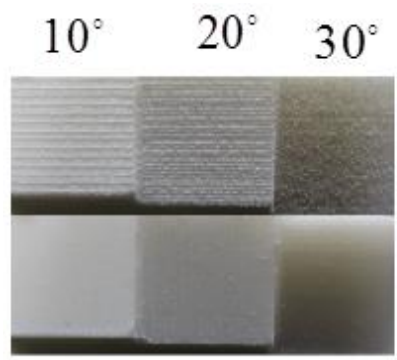

a

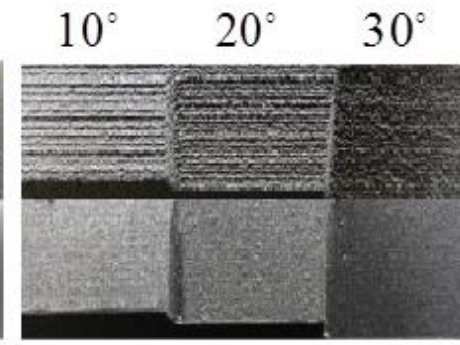

b

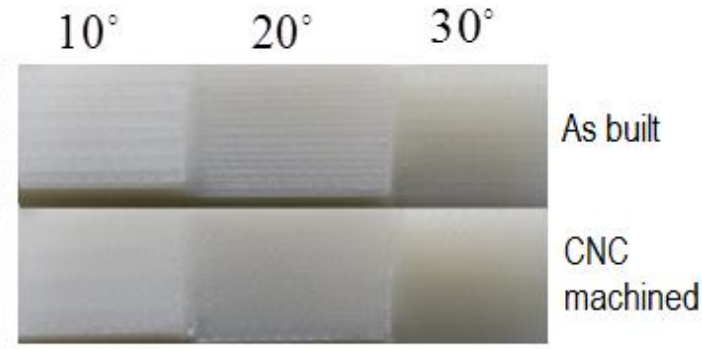

C

Figure 19: CNC machined Nylon (a), Alumide® (b) and ABS (c) test pieces

Chemical treatment (Figures $12 \mathrm{~g}$ and 20) consisted of dissolving the surfaces of the ABS test piece using acetone for a period of 60 seconds at room temperature was found to produce excellent uniform surface distribution of $\pm 0.1 \mathrm{~mm}$ from the deviation range from the geometry of the "as built" test piece. Despite the presence of $(-0.183$ to -0.1$) \mathrm{mm}$ negative deviation range testifying to the shrinkage effect as observed by Galantucci et al. (2009), the features with small protrusions, round cavities, sharp edges and top surfaces of the conical features all retained excellent dimensional accuracy with a proportion of $90 \%$ of the total number of touch probe scanned points on the ABS surfaces.

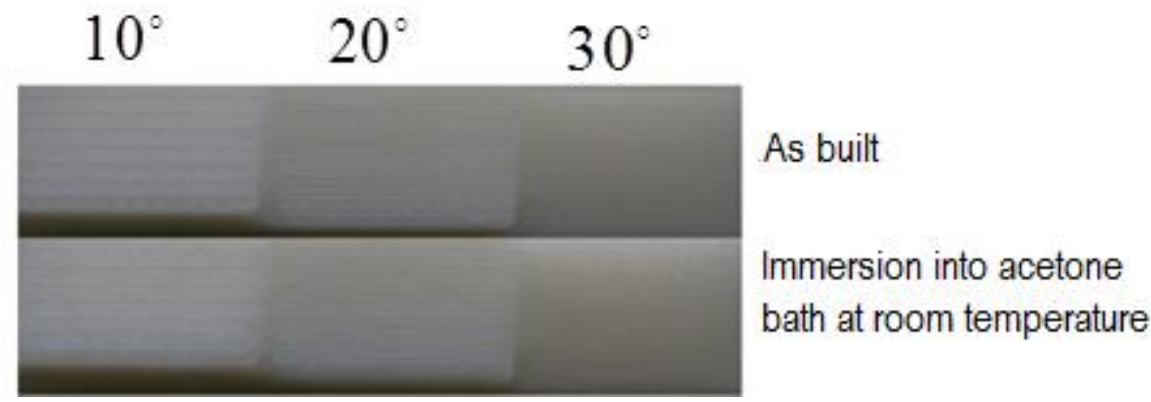

Figure 20: Chemically treated ABS test pieces into acetone bath

McCullough and Yadavilli (2013) realised that the removal of ABS material during an acetone bath caused pitting and subsequent deposition of ABS on the surface thus forming peaks. This effect is also observed in the current investigation where positive deviation ranges $(+0.1$ to +0.348$)$ are displayed on the top horizontal surface of ABS chemically treated test piece (Figure 12g).

\section{Conclusions}

Although there is published work regarding the improvement of surface finishing of AM components using various post processing techniques (Pandey et al., 2003; Schmid et al., 2009; Galantucci et al., ibid.; Addanki et al., 2012; De Beer et al., 2012; Daneshmand and Aghanajafi, 2012; Kuo and Su, 2013; Azhar and Anoop, 2014; Raja, 2016), very little research has been done to investigate the detrimental effects of improving the surface 
roughness and its influence on the dimensional accuracy of AM parts. In this work, the Chisquare test $\left(\chi^{2}\right)$ and statistic Z-observed $\left(Z_{o b s}\right)$ test methods confirmed that there is a significant difference between the deviation range proportions when comparing the "as built" part to any one of the six post processed parts. Within a $\pm 0.1 \mathrm{~mm}$ deviation range, spray painting was generally characterized by consistency in a uniform distribution of excessive positive deviations; and with hand finishing being dominated by inconsistency in deviation ranges. Despite the rounding of sharp corners and the removal of small protrusions, the dimensional accuracy of relatively wide surfaces of nylon or Alumide ${ }^{\circledR}$ test pieces was not significantly affected by the tumbling or shot peening processes. The immersion of ABS test pieces into an acetone bath produced the best dimensional accuracy. Improvement of surface finish of relatively wide surfaces of the test pieces through CNC machining influenced the dimensional accuracy of the test piece surfaces negatively, mainly due to an error in setting and calibration of the cutting parameters in Z-direction on the CNC machine. This error could have been prevented by setting individual calibration and cutting parameters for each angled surface, but this would have increased the cost of machining to an unacceptable level. Tumbling or shot peening should not be used for improving the surface finish of FDM ABS parts as the dimensional accuracy of the part is negatively affected by the two techniques that are deemed too harsh. In conclusion, service bureaus that produce prototypes and end use functional parts through AM are recommended to apply the findings of this investigation to real world projects.

\section{Future work}

The preliminary statistical data obtained from the touch probe scanning technique were generalized to the entire test piece and are not specific to an individual surface inclination angle. Future work should concentrate on acquiring the dimensional deviation ranges based on each angled surface to establish the effect of surface inclination angle on shrinkage of the "as built" part and to identify is there any correlation between the dimensional accuracy and the surface finish of each post processing technique. To establish the degree of repeatability of results, future research could focus on shot peening and tumbling process parameters that influence the surface finish and dimensional accuracy of the parts. The effect of post processing techniques on mechanical properties of tumbled and shot peened nylon and Alumide ${ }^{\circledR}$ and chemically treated ABS parts is also of interest for future study.

\section{Acknowledgement}

This research was supported by Central University of Technology, Free State (CUT) through the Centre for Rapid Prototyping and Manufacturing (CRPM) and Product Development Technology Station (PDTS) as well as De Montfort University (UK). The authors acknowledge also the support of University of Rwanda-College of Science and Technology (UR-CST). Funding for this work was made available by the South African Research Chairs Initiative of the Department of Science and Technology and National Research Foundation of South Africa (Grant №97994) and the Collaborative Program in Additive Manufacturing (Contract №CSIR-NLC-CPAM-15-MOA-CUT-01).

\section{References}

1. Addanki, S.R., Medha, A.D., Venkatesh, J.V.L. \& Deepesh, O. (2012), "Investigation of post processing techniques to reduce the surface roughness of fused deposition modelled parts", International Journal of Mechanical Engineering and Technology (IJMET), Vol. 3, Issue 3, pp. 531-544 
2. Akande, O.S. (2015), "Dimension accuracy and surface finish optimization of fused deposition modelling parts using desirability function analysis", International Journal of Engineering Research \& Technology (IJERT), Vol. 4 No 4, pp. 196-202.

3. Anoop, K.S., Ohdar, R.K. \& Mahapatra S.S. (2009), "Improving dimensional accuracy of Fused Deposition Modelling part using Taguchi method", Material and Design, Vol. 30, pp. 4243-4252.

4. Anoop, K.S., Vedansh, C., Saurav, D. \& Siba, S.M., 2011, Optimization of process parameters in Fused Deposition Modeling using weighted principal component analysis, Journal of Advanced Manufacturing Systems 10(2), 241-259.

5. Azhar, E. and Anoop, K.S. (2014), "Metallization of FDM parts using the chemical deposition technique", Coatings, Vol. 4, pp. 574-586.

6. Bual, G.S. and Kumar, P. (2014), "Method to improve surface finish of parts produced by fused deposition modelling", Manufacturing Science and Technology, Vol. 2, issue 3, pp. 51-55.

7. Daneshmand, S. and Aghanajafi, C. (2012), "Description and modelling of additive manufacturing technology for aerodynamic coefficient measurement", Journal of mechanical Engineering, Vol. 58 No 2, pp. 125-133.

8. Daneshmand, S., Aghanajafi, C. and Shahverdi, H. (2013), "Investigation of rapid manufacturing technology effect on aerodynamics properties", Tehnicki Vjesnik, Vol. 20 No 3, pp. 425-433.

9. De Beer, D.J., Becker, L., Van del Walt, P., Mauchline, D., Campbell, R.I. and Dean, L.T. (2012), "Additive manufacturing of alumide jewellery", Proceedings of 13th Annual RAPDASA Conference in Pretoria, South Africa, 2012, pp. 11.

10. De Beer, N. (2013), "Additive manufacturing -Turning mind into matter-Industry evaluation and recommendations report", Center for Applied Competitiveness Technologies (CACT), Sierra College, California, USA, 2013.

11. Dzullijah, I., Songlin, D. and Shoujin, S. (2014), "Roughness prediction for FDM produced surfaces", International Conference Recent Treads in Engineering \& Technology (ICRET) in Batan, Indonesia, 2014, pp. 13-14.

12. EOS GmbH (2005), EOSINT P385 Laser -sintering system for plastics-Operation PSW 3.2 .

13. Galantucci, L.M., Bodi, I., Kacani, J. and Lavecchia, F. (2015), "Analysis of dimensional performance for 3D open-source printer based on fused deposition modelling technique", Procedia CIRP, Vol. 28, pp. 82-87.

14. Galantucci, L.M., Lavecchia, F. and Percoco, G. (2009), "Experimental study aiming to enhance the surface finish of fused deposition modelled parts", CIRP Annalsmanufacturing Technology, Vol. 58 No 1, pp. 189-192.

15. Goodridge, R.D., Tuck, C.J. and Hague, R.J.M. (2012), "Laser Sintering of polyamides and other polymers", Progress in Materials Science, Vol. 57 No 2, pp. 229-267.

16. Kitsakis, K., Alabey, P., Kechagias, N. and Vexevanidis, N. (2016), "A study of dimensional accuracy obtained by low cost 3D printing for possible application in medicine", $20^{\text {th }}$ Innovation Manufacturing Engineering and Energy conference (IManEE 2016), IOP Conf. series: Materials Science and Engineering, Vol. 161, pp. 1-6.

17. Krolczyk, G., Raos, P. and Legutko, S. (2014), "Experimental analysis of surface roughness and surface texture of machined and fused deposition modelled parts", Tehnicki Vjesnik, Vol. 21 No 1, pp. 217-221.

18. Kruth, J.P., Levy, G., Schinder, R., Craeghs, T. and Yasa, E. (2008), "Consolidation of polymers by Selective Laser Sintering". [s.I.].

19. Kuo, C.C and Su, S.J. (2013), "A simple method for improving surface quality of rapid prototype", Indian Journal of Engineering Sciences, Vol. 20, pp. 465-470.

20. Latiff, Z.A., Rahman, M.R.A. and Saad, F. (2013), "Dimensional accuracy evaluation of rapid prototyping fused deposition modelling process of FDM200mc machine on basic engineering profile", Applied Mechanics and Materials (AMM), pp. 96-100.

21. Lieneke, T., Denzer, V., Adam, G.A.O. and Zimmer, D. (2016), "Dimensional tolerances for additive manufacturing: Experimental investigation for Fused Deposit modelling", $14^{\text {th }}$ 
CIRP conference on Computer Aided Tolerencing (CAT), Procedia CIRP, Vol. 43, pp. 286-291.

22. Manfredi, D., Calignano, F., Krishnan, M., Canali, R., Ambrosio, E.P., Biamino, S., Urgues, D., Pavese, M. and Fino, P. (2014), "Additive manufacturing of Al alloys and Aluminium Matrix Composites (AMCs)", INTECH open science/open minds.

23. McCullough, E.J. and Yadavalli, V.K. (2013), "Surface modification of fused deposition modelling ABS to enable rapid prototyping of biomedical microdevices", Journal of Materials Processing Technology, Vol. 213, pp. 947-954.

24. Mireles, J., Adame, A., Espalin, D., Medina, F., Winker, R., Hoppe, T., Zinniel, B. and Wicker, R. (2011), Reviewed August 17th 2011, "Analysis of sealing methods for FDM fabricated parts", Couri Symposium, pp. 185-196.

25. Montgomery, D.C. and Runger, G.C. (2011), Applied statistics and probability for engineers, John Wiley \& Sons, Inc. $5^{\text {th }}$ ed., USA.

26. Nancharaiah, T., Ranga, R. and Ramachandra, V.R. (2010), "An experimental investigation on surface quality and dimensional accuracy of FDM components", International Journal of Emerging Technologies, Vol. 1 No 2, pp. 106-111.

27. Noriega, A., Blanco, D., Alvarez, B.J. and Garcia, A. (2013), "Dimensional accuracy improvement of FDM square cross-section parts using artificial neural networks and optimization algorithm", International Journal of Advanced Manufacturing Technolog, Vol. 69, pp. 2301-2313.

28. Pandey, P.M., Reddy, N.V., \& Dhande, S.G. (2003), "Improvement of surface finish by staircase machining in fused deposition modelling", Journal of Material Processing Technology, Vol. 132, Issue 1-3, pp. 323-331.

29. Pham, D.T., Dotchev, K.D. and Yusoff, W.A.Y. (2008), "Deterioration of polyamide powder properties in laser sintering process", Journal of Mechanical Engineering Science, Vol. 222, pp. 2163-2176.

30. Raghunath, N. and Pandey, M.P. (2007), "Improving accuracy through shrinkage modelling by using Tagushi method in Selective laser Sintering", International Journal of Machine Tools \& Manufacture, Vol. 47, pp. 985-995.

31. Raja, K. (2016), A review on chemical processes for plastics substrates used in engineering industries, International Journal of ChemTech Research, Vol. 9, issue 7, pp. 354-365.

32. Schmid, M., Simon, C. \& Levy, G.N. (2009), "Finishing of SLS-parts for rapid manufacturing (RM)-a comprehensive approach", INSPIRE, pp. 1-10.

33. Shirazi, S.F.S., Gharehkhani, S., Mehrali, M., Yarmand, H., Metsalaar, H.S.C., Kadri, N.A. and Osman, N.A.A. (2015), "A review on powder-based additive manufacturing for tissue engineering: selective laser sintering and inkjet 3D printing", Science and Technology of Advanced Materials, Vol. 16, pp. 1-20.

34. Shrivastava, V., Parida, S.K. \& Pandey, P.M. (2010), "Surface roughness studies in Selective Laser Sintering of Glass Filled Polyamide", Proceedings of $36^{\text {th }}$ International MATADOR Conference, Manchester 2010.

35. Singh, R. (2013), "Some investigations for small-sized product fabrications with FDM for plastic components", Rapid Prototyping Journal, Vol. 19, Issue 1, pp. 58-63.

36. Tanay, V.D., Prashant, M.K., Gaurav, C.N. \& Vishal, N.B. (2013), "Multi objective optimization of built orientation for rapid prototyping of connecting rod", International Journal of scientific research and management, Vol. 1, Issue 1, pp. 13-18.

37. Urednik, (2013), "Alumide ${ }^{\circledR}$-Polyamide carbon fiber-reinforced", available at www.3dimpuls.com (accessed 21 July 2014).

38. Zarringhalam, H., Hopkinson N., Kamperman N.F. \& de Vlieger J.J. (2006), "Effect of processing on microstructure and properties of SLS Nylon 12", Material Science and Engineering, pp. 172-180. 